\title{
Mating System in the Brown Rot Pathogens Monilinia fructicola, M. laxa, and M. fructigena
}

\author{
Domenico Abate, Rita M. De Miccolis Angelini, $†$ Caterina Rotolo, Stefania Pollastro, and Francesco Faretra
}

First, second, third, fourth, an fifth authors: Department of Soil, Plant and Food Sciences, University of Bari Aldo Moro, via Amendola 165/A, 70126 Bari, Italy; and second, fourth, and firth authors: SELGE Network of Public Research Laboratories, via Amendola 165/A, 70126 Bari, Italy.

Accepted for publication 14 May 2018.

\begin{abstract}
Monilinia fructicola, M. laxa, and M. fructigena are the most important pathogens responsible for brown rot disease of stone and pome fruits. Information on their mating system and sexual behavior is scant. A mating-type-specific PCR-based assay was developed and applied to 155 Monilinia isolates from 10 countries and 10 different host plants. We showed that single isolates carry only one of two opposite idiomorphs at the MAT1 locus consistent with a heterothallic mating system for all three species. MAT1-1 and MAT1-2 mating types were detected in similar proportions in samples of isolates of each species and hence there do not appear to be genetic obstacles to the occurrence of sexual reproduction in their populations. Inter simple sequence repeat markers suggested that asexual reproduction is prevalent, but that sexual recombination occurs in $M$. fructicola populations in Italy. The genetic architectures of the MATI loci of the three pathogens were analyzed.

MAT1-1 and MAT1-2 idiomorphs are flanked upstream and downstream by the APN2 and SLA2 genes and resemble those of Botrytis cinerea and other heterothallic fungi in the family Sclerotiniaceae. Each idiomorph contains a specific couple of genes, MAT1-1-1 (with alpha-box domain) and MAT1-1-5 in MAT1-1, and MAT1-2-1 (with HMG-box domain) and MAT1-2-10 in MAT1-2. Small gene fragments (dMAT1-1-1 and dMAT12-1) from the opposite idiomorph were detected close to their flanking regions. Constitutive expression of the four MAT1 genes during vegetative growth was ascertained by transcriptomic analysis (RNA-Seq). Antisense transcription of the MAT1-1-1 and MAT1-2-1 genes and intergenic transcribed regions of the MATI locus were detected. These results represent new insights into the mating systems of these three economically-important pathogens which could contribute to improve the knowledge on their population biology.
\end{abstract}

Brown rot is an important disease affecting stone- and pomefruits in the field as well as in postharvest (Byrde and Willetts 1977). The disease is caused by one or more of six closely related species of Monilinia: M. fructicola (G. Winter) Honey (Mordue 1979a), M. fructigena Honey ex Whetzel (Mordue 1979b), M. laxa (Aderhold \& Ruhland) Honey (Mordue 1979c), M. polystroma G.C.M. Leeuwen (van Leeuwen et al. 2002), M. mumecola Y. Harada, Y. Sasaki \& T. Sano (Harada et al. 2004), and M. yunnanensis M.J. Hu \& C.X. Luo (Hu et al. 2011).

M. fructicola, M. laxa, and M. fructigena are the major causal agents of brown rot. M. laxa is the most common brown rot pathogen and occurs in many places worldwide (https://www.cabi. org/isc/datasheet/34749). M. fructigena is mostly restricted to European countries and parts of Asia, but is absent from South America, Australia, and New Zealand (https://www.cabi.org/isc/ datasheet/34747). Both species are indigenous to Europe and are associated with European brown rot, being the only species present in Europe before the new millennium. M. fructicola is responsible for the American brown rot and originally occurred in North and South America, Japan, Australia, New Caledonia, and New Zealand

†Corresponding author: R. M. De Miccolis Angelini;

E-mail: ritamilvia.demiccolisangelini@uniba.it

Funding: This research was carried out in the framework of the project 'Epidemiology, genetics of plant pathogens and development of molecular diagnostic methods' granted by the University of Bari. The Ph.D. student D. Abate was granted by Sumitomo Chemical Italia. The funding company had no role in the design of the study and collection, analysis, and interpretation of data and in writing the manuscript.

*The $\boldsymbol{e}$-Xtra logo stands for "electronic extra" and indicates that two supplementary figures and one supplementary table are published online.

Modified 20 Mar 2019.

(C) 2018 The American Phytopathological Society but now it occurs worldwide (https://www.cabi.org/isc/datasheet/ 34746). In Europe, it is recommended for regulation as a quarantine pest by the European and Mediterranean Plant Protection Organization and is included in the A2 List (https://gd.eppo.int/taxon/ MONIFC/categorization). M. fructicola was first introduced to Europe in 2001 in France (OEPP/EPPO 2002), and subsequently, the pathogen was reported in restricted areas or with sporadic occurrence in numerous other countries (Riccioni and Valente 2015; https://gd.eppo.int/taxon/MONIFC/distribution). In Italy, M. fructicola was first detected in Piedmont (North Italy) (Pellegrino et al. 2009), and successively, it was reported in Emilia-Romagna and Lazio (Central Italy) (Martini et al. 2013) and in South Italy (Abate et al. 2018).

In contrast to other fungi belonging to family Sclerotiniaceae, such as Botrytis cinerea Pers. and Sclerotinia sclerotiorum (Lib.) de Bary, knowledge on the sexual behavior and mating system in Monilinia species is scant. Apothecia, rarely reported for $M$. fructigena and $M$. laxa, are commonly differentiated by M. fructicola and analysis of variation in populations of the fungus through classical and molecular markers suggests that sexual recombination occurs in Europe and the United States (De Cal et al. 2014; Free et al. 1996; Holtz et al. 1998; Jänsch et al. 2012; Michailides et al. 2007; Ogawa and English 1991; Villarino et al. 2012; Willetts and Harada 1984). Apothecia of $M$. fructicola and $M$. fructigena could be obtained under laboratory conditions, allowing genetic analysis of meiotic progenies (Batra 1991; Free et al. 1996).

The MAT1 locus controls the mating system in Ascomycetes (Debuchy and Turgeon 2006). In heterothallic fungi, cross-compatible mating types carry opposite idiomorphs, i.e., two alternative highly divergent sequences containing unrelated MAT1 genes at the same chromosomal location. In homothallic fungi, single isolates carry both idiomorphs (Martin et al. 2010). The family Sclerotiniaceae include both homothallic and heterothallic species. For instance, $B$. cinerea 
displays a bipolar heterothallism and the MATl-1 or the MATl-2 idiomorphs are singly carried by self-sterile individuals; alternatively, S. sclerotiorum displays homothallism and the corresponding MAT1-1 and MAT1-2 idiomorphs are closely linked end-to-end at a single MAT1 locus in self-fertile individuals (Amselem et al. 2011; De Miccolis Angelini et al. 2016; Faretra et al. 1988).

This work was aimed at (i) developing a molecular assay for mating-type assessment in Monilinia isolates; (ii) evaluating the presence and distribution of mating-type-specific genes in M. laxa, $M$. fructicola, and $M$. fructigena isolates from different countries and host plants; (iii) investigating the occurrence of sexual recombination in $M$. fructicola populations in Italy; and (iv) characterizing the genetic organization of the MAT1 loci in the three Monilinia species.

\section{MATERIALS AND METHODS}

Fungal isolates and DNA extraction. Ninety isolates of Monilinia spp. from Italy and 65 isolates from different origins were used in this study (Table 1). The isolates, derived from single germinating conidia, were routinely grown on potato dextrose agar (PDA, ingredients per liter of distilled water: infusion from $200 \mathrm{~g}$ of peeled and sliced potatoes kept at $60^{\circ} \mathrm{C}$ for $1 \mathrm{~h}, 20 \mathrm{~g}$ of dextrose, adjusted at $\mathrm{pH} 6.5,20 \mathrm{~g}$ of agar Oxoid No. 3) at $24 \pm 1^{\circ} \mathrm{C}$ in the darkness. For long-term storage, suspensions of conidia and mycelium of each isolate were maintained at $-80^{\circ} \mathrm{C}$ in $10 \%$ glycerol and revitalized on PDA just before use.

Genomic DNA was extracted and purified from mycelium grown on cellophane disks overlaid on PDA per 4 days at $24 \pm 1{ }^{\circ} \mathrm{C}$, according to De Miccolis Angelini et al. (2010). In brief, mycelium collected by scraping the cellophane was powdered under liquid nitrogen and added with $600 \mu \mathrm{l}$ of CTAB buffer (100 mM Tris-Cl, pH 8.0; $1.4 \mathrm{M} \mathrm{NaCl} ; 20$ mM EDTA, pH 8.0; $2 \%$ cetyldimethylethylammonium bromide [wt/vol]; and $0.2 \% \beta$-mercaptoethanol [vol/vol]). Samples were then frozen and thawed three times using liquid nitrogen and a water bath at $75^{\circ} \mathrm{C}$, and then incubated at $75^{\circ} \mathrm{C}$ for $1 \mathrm{~h}$. After chloroform extraction, the clear supernatant was transferred to a new tube and precipitated with isopropanol at $-80^{\circ} \mathrm{C}$ per $30 \mathrm{~min}$. After centrifugation $\left(14,000 \mathrm{rpm}\right.$ for $15 \mathrm{~min}$ at $\left.4^{\circ} \mathrm{C}\right)$, the nucleic acid pellet was washed with cold $70 \%$ ethanol, air-dried, and dissolved in TE (10 mM Tris-Cl; $1 \mathrm{mM}$ EDTA, $\mathrm{pH}$ 8.0). Samples were then treated with $0.1 \mu \mathrm{g} \mathrm{l}^{-1}$ of DNase-free pancreatic RNase (Sigma-Aldrich, Milan, Italy) for $2 \mathrm{~h}$ at $37^{\circ} \mathrm{C}$, precipitated by the addition of $0.6 \mathrm{vol}$ of $5 \mathrm{M}$ ammonium acetate and 2 vol of cold absolute ethanol. The final DNA pellets, washed with $70 \%$ ethanol and air-dried, were dissolved in water and stored at $-80^{\circ} \mathrm{C}$ until use.

Molecular assay for mating type. Primer pairs were designed on the conserved regions of the MAT1 locus in two closely related species, the homothallic S. sclerotiorum and the heterothallic

TABLE 1. Origin of Monilinia isolates used in this study

\begin{tabular}{|c|c|c|c|c|}
\hline$\frac{\text { Species }}{\text { M. fructicola }}$ & Isolate code ${ }^{a}$ & Location & Host plant & Year \\
\hline \multirow[t]{18}{*}{ M. fructicola } & $\begin{array}{l}\text { Mfrc69, Mfrc77, Mfrc78, Mfrc83, Mfrc88, } \\
\text { Mfrc93 }\end{array}$ & Italy (Caserta, Campania) & Cherry & 2014 \\
\hline & $\begin{array}{l}\text { Mfrc106, Mfrc111, Mfrc113, Mfrc114, } \\
\text { Mfrc118, Mfrc123, Mfrc129, Mfrc140, Mfrc144, } \\
\text { Mfrc145 }\end{array}$ & Italy (Bisceglie, Apulia) & Cherry & 2014 \\
\hline & $\begin{array}{l}\text { Mfrc146, Mfrc147, Mfrc148, Mfrc149, Mfrc150, } \\
\text { Mfrc151, Mfrc152, Mfrc153, Mfrc154, Mfrc155, } \\
\text { Mfrc156, Mfrc157, Mfrc158, Mfrc159, Mfrc160, } \\
\text { Mfrc161, Mfrc163, Mfrc164, Mfrc165, } \\
\text { Mfrc168, Mfrc177, Mfrc180, Mfrc186, } \\
\text { Mfrc190, Mfrc197, Mfrc210, Mfrc214, } \\
\text { Mfrc222, Mfrc266, Mfrc273, Mfrc275 }\end{array}$ & Italy (Tursi, Basilicata) & Plum & 2014 \\
\hline & Mfrc228, Mfrc230, Mfrc233 & & Donut Peach & 2014 \\
\hline & Mfrc247, Mfrc261, Mfrc262, Mfrc265 & Italy (Policoro, Basilicata) & Donut Peach & 2014 \\
\hline & $\begin{array}{l}\text { Mfrc301, Mfrc303, Mfrc305, Mfrc312, Mfrc320, } \\
\text { Mfrc321, Mfrc322 }\end{array}$ & Italy (Gioia del Colle, Apulia) & Cherry & 2014 \\
\hline & Mfrc426 & France (Provence-Alpes-Côtes d'Azur) & Apricots & 2010 \\
\hline & Mfrc408 & Serbia (Osečina, Kolubara) & Plum & 2013 \\
\hline & Mfrc412 & Serbia (Požarevac, Braničevo) & Cherry & 2015 \\
\hline & Mfrc414 & Serbia (Golobok, Smederevska Palanka) & Peach & 2016 \\
\hline & Mfrc415 & Serbia (Šabac, Mačva) & Sour cherry & 2016 \\
\hline & Mfrc391, Mfrc392, Mfrc393 & Spain (Lleida, Alcarràs) & Unknown & 2013 \\
\hline & Mfrc394 & Spain (Lleida, Albesa) & Unknown & 2009 \\
\hline & Mfrc395 & & Unknown & 2010 \\
\hline & Mfrc396, Mfrc400 & Spain (Lleida, Alfarràs) & Unknown & 2009 \\
\hline & Mfrc397 & Spain & Unknown & 2011 \\
\hline & Mfrc398 & & Unknown & 2014 \\
\hline & Mfrc399 & & Unknown & 2015 \\
\hline
\end{tabular}

a The isolate Mfrc534 was supplied by F. Nigro (DiSSPA - University of Bari, Italy); the isolates from Mfrc347 to Mfrc358 were supplied by G. Schnabel (Clemson University, USA); Mfrc401 to Mfrc405 by G. C. M. Van Leeuwen (National Reference Centre - NPPO, The Netherlands); Mfrg344 to Mfrg345 by M. Mari (University of Bologna, Italy); Mfrc426 to Mfrc430 by C. Guinet (Agence nationale de sécurité sanitaire de l'alimentation, de l'environnement et du travail - ANSES); Mfrc362 to Mfrc365 by G. Karaoglanidis (Aristotle University of Thessaloniki, Greece); Mfrc407, Mfrc408, Mfrc412, Mfrc414, Mfrc415 by J. Hrustic (Istitute za Pesticide, Serbia); Mfrc391 to Mfrc400 by A. De Cal (Instituto Nacional de Investigación y Tecnología Agraria y Alimentaria, Spain); Mfrc326 to Mfrc333 and Mfrc335 to Mfrc339 by T. Michailides (University of California, Berkeley, USA); Mfrc416, Mfrc418 to Mfrc420 and Mfrc424 by B. Weir (Landcare Research Manaaki Whenua, New Zealand); and Mfrc435 to Mfrc438 by L.-Y. Guo (China Agricultural University, China). The isolates Mlax509 and Mfrg510 correspond to CBS 101503 and CBS 101501, respectively. The Monilinia isolates used in setting up the PCR assay for mating type are underlined and those used for the molecular characterization of the MAT1 loci are in bold. 
B. cinerea, with the aim to amplify portions of the mating-type genes in Monilinia spp. since no information was available at the beginning of the work. In detail, nucleotide MAT1 sequences from S. sclerotiorum (JQ815883.1) and B. cinerea (MAT1-1, KF944385.1; MAT1-2, KF944386.1) were aligned using SeqMan Pro (Lasergene v.14.1, DNASTAR Inc., Madison, WI) and primer pairs, 1A and 1B specific for the MAT1-1-1 gene and 2A and 2B specific for the MAT1-2-1 gene, were designed using the Primer3 software (Rozen and Skaletsky 2000) (Table 2). The primer pairs were preliminary tested on seven isolates per species (underlined in Table 1).

PCR amplifications were performed in a GeneAmp PCR System 9700 thermal cycler (Perkin-Elmer, Norwalk, CT) using the following conditions: $5 \mathrm{~min}$ at $94^{\circ} \mathrm{C}, 30$ cycles of $1 \mathrm{~min}$ at $94^{\circ} \mathrm{C}$, $1 \mathrm{~min}$ at $54^{\circ} \mathrm{C}$ (Table 2), and $1 \mathrm{~min}$ at $72^{\circ} \mathrm{C}$, followed by a final extension of $7 \mathrm{~min}$ at $72^{\circ} \mathrm{C}$. Reaction mixtures $(50 \mu \mathrm{l})$ consisted of $1 \times$ LA PCR Buffer II ( $\mathrm{Mg}^{2+}$ free $), 2 \mathrm{mM} \mathrm{MgCl}_{2}, 0.2 \mathrm{mM}$ each dNTP, $2 \mathrm{U}$ of TaKaRa LATaq (all PCR reagents were from Takara Bio Inc., Otsu, Shiga, Japan), $0.1 \mu \mathrm{M}$ of each primer, and 0.1 to $0.2 \mu \mathrm{g}$ of DNA template. Negative control, in which water was used instead of the target DNA, was always run to detect potential contaminations. Aliquots $(5 \mu \mathrm{l})$ of PCR products were sizeseparated on $1.5 \%$ agarose (Bio-Rad Laboratories, Hercules, CA), added with $0.05 \mu \mathrm{ml}^{-1}$ GelRed (Biotium, Hayward CA), in 1×TAE (40 mM Tris; $20 \mathrm{mM}$ acetic acid; and $1 \mathrm{mM} \mathrm{Na} 2$ EDTA, $\mathrm{pH}$ 8.0) buffer at $110 \mathrm{~V}$ for $110 \mathrm{~min}$. Amplicons were purified with Quantum
Prep PCR Kleen Spin columns (Bio-Rad Laboratories) andsubjected to direct sequencing in both forward and reverse directions by external service (Genewiz, Takeley, UK) using the same primers as for PCR. New primer pairs ( $2 \mathrm{C}-2 \mathrm{~F}$, Table 2$)$ were designed on the conserved regions of the obtained MAT1-2 amplicons in the three Monilinia species for improving reaction specificity and sensitivity. All primers were synthesized by external service (Macrogen Inc., Seoul, Republic of Korea). Lasergene was used for sequence analysis and BLASTn and BLASTx were used for similarity search and multiple sequence alignments with sequences available in NCBI GenBank (https://www.ncbi.nlm.nih.gov).

For the assessment of mating type of M. fructicola, M. laxa, and $M$. fructigena isolates, PCR conditions were the same as above but the reaction mixture (final volume of $25 \mu \mathrm{l}$ ) contained $1 \times$ Green GoTaq Flexi buffer ( $\mathrm{Mg}^{2+}$ free), $2 \mathrm{mM} \mathrm{MgCl}_{2}, 75 \mu \mathrm{M}$ each dNTP, $1.25 \mathrm{U}$ of GoTaq DNA Polymerase (all from Promega Co., Madison, WI), $0.5 \mu \mathrm{M}$ of each primer (pairs $1 \mathrm{~B}$ and $2 \mathrm{C}$, Table 2), and $0.1 \mu \mathrm{g}$ of DNA template. PCR products were visualized by electrophoresis as previously described. Frequencies of MAT1-1 and MAT1-2 idiomorphs on total count in each species were tested by the $\chi^{2}$ test to show possible deviations from the $1: 1$ ratio.

Inter simple sequence repeat (ISSR) profiling and linkage disequilibrium analysis in M. fructicola. Nine isolates (Mfrc77, Mfrc78, Mfrc106, Mfrc123, Mfrc148, Mfrc150, Mfrc233, Mfrc320, and Mfrc321) were used in a pilot experiment to screen ISSR

TABLE 1. (Continued from previous page)

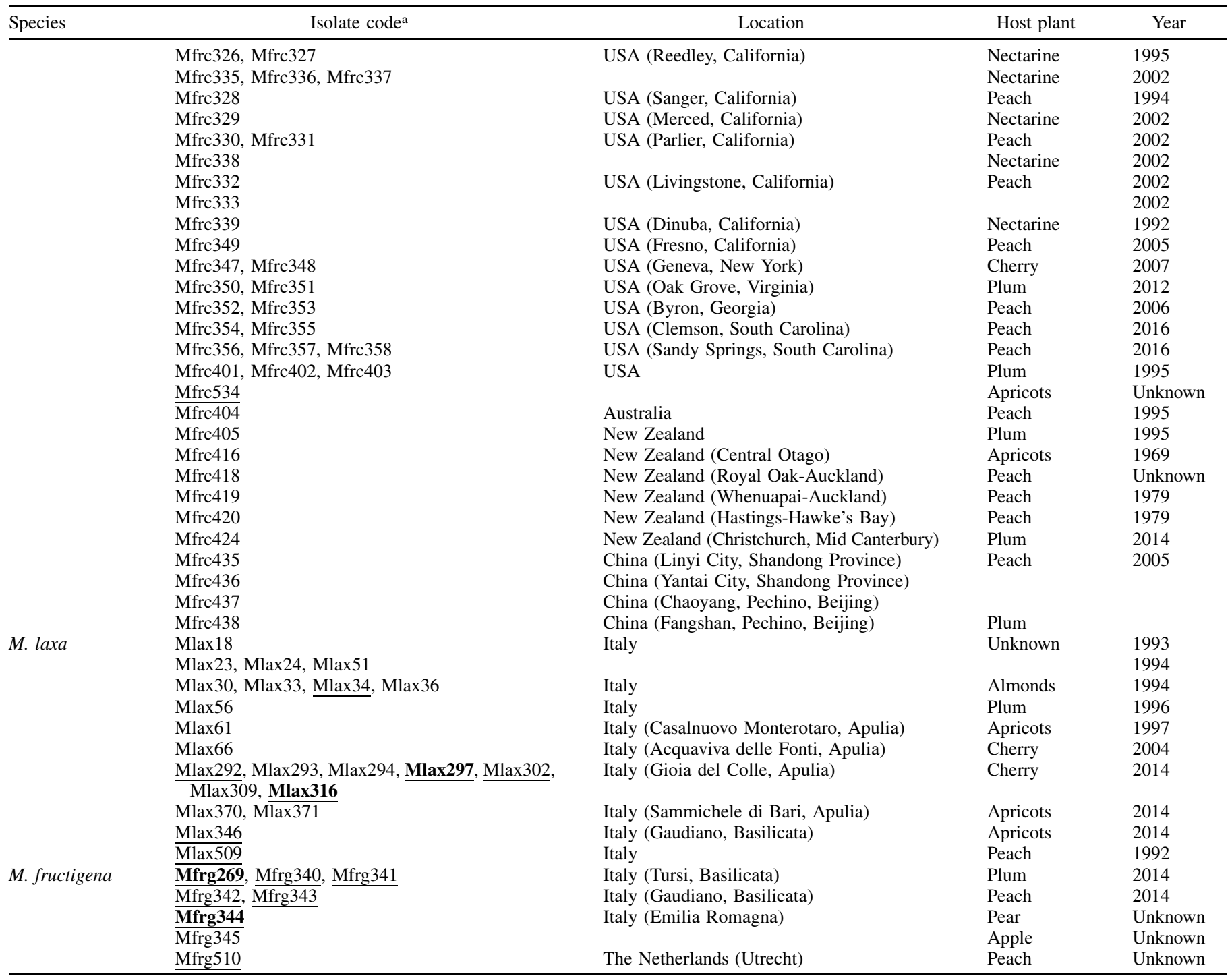


primers. Fifteen ISSR primers previously reported to generate polymorphic fingerprinting patterns in fungi were screened: Mf-1 $(\mathrm{AT})_{8}, \mathrm{Mf}-2(\mathrm{AC})_{8}, \mathrm{Mf}-3$ (AAG) $)_{5}, \mathrm{Mf}-6(\mathrm{AAT})_{5}, \mathrm{Mf}-4(\mathrm{AG})_{8}, \mathrm{Mf}-5$ $(\mathrm{AAC})_{5}, \mathrm{Mf}-7$ (AAG) $)_{8}$ (Lim et al. 2004), Mf-8 (AG) ${ }_{8} \mathrm{C}$, Mf-9 $(\mathrm{GACA})_{4}$, M-13-Mf (GAGGGTGGCGGCGGTTCT) (Ma et al.

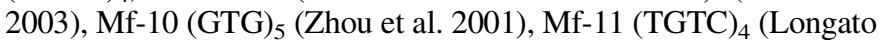
and Bonfante 1997), SSR-2 (ACTG) $)_{4}$, SSR-5 (GACAC) ${ }_{4}$, and SR 10 $(\mathrm{CAC})_{5}$ (Jana et al. 2005). All primers were synthesized by Macrogen Inc. and PCR amplifications were performed according to Villarino et al. (2012). The PCR mix (final volume $25 \mu \mathrm{l}$ ) consisted of $1 \times$ Green GoTaq Flexi Buffer ( $\mathrm{Mg}^{2+}$ free), $2 \mathrm{mM}$ or $2.5 \mathrm{mM}$ (Mf-7, Mf-8, and Mf-9) $\mathrm{MgCl}_{2}, 0.2 \mathrm{mM}$ each dNTP, $1 \mathrm{U}$ (Mf-2), $1.5 \mathrm{U}$, or $2.25 \mathrm{U}$ (Mf-7) of GoTaq DNA Polymerase (all reagents from Promega Co.), $1 \mu \mathrm{M}$ or $2 \mu \mathrm{M}$ (Mf-2 and Mf-7) primer, and $50 \mathrm{ng}$ of DNA template. Standard PCR conditions were as follows: $3 \mathrm{~min}$ at $95^{\circ} \mathrm{C}$ for initial denaturation; 40 cycles of $1 \mathrm{~min}$ at $94^{\circ} \mathrm{C}, 1 \mathrm{~min}$ at $50^{\circ} \mathrm{C}, 45^{\circ} \mathrm{C}$ (Mf-8), or $36^{\circ} \mathrm{C}$ (Mf-9), 1 min at $72^{\circ} \mathrm{C}$; ending with $10 \mathrm{~min}$ at $72^{\circ} \mathrm{C}$ and a final hold at $4^{\circ} \mathrm{C}$. For the Mf- 2 primer, PCR conditions were as follows: $3 \mathrm{~min}$ at $95^{\circ} \mathrm{C}$ for initial denaturation; 35 cycles of $30 \mathrm{~s}$ at $94^{\circ} \mathrm{C}, 30 \mathrm{~s}$ at $53^{\circ} \mathrm{C}, 1 \mathrm{~min}$ at $72^{\circ} \mathrm{C}$; ending with $10 \mathrm{~min}$ at $72^{\circ} \mathrm{C}$ and a final hold at $4^{\circ} \mathrm{C}$. Each reaction was performed twice, and PCR products separated on 3\% agarose gel added with $0.05 \mu \mathrm{l} \mathrm{ml} l^{-1}$ of GelRed (Biotium) in 1× TAE buffer and photographed with a Gel Doc 1000 System (Bio-Rad Laboratories). A 100-bp DNA Ladder (New England Bio-Labs, Beverly, CA) and a EZ Load 500-bp Molecular Ruler (Bio-Rad Laboratories) were used as molecular size markers. The experiments were repeated at least twice. Thirteen primers that generated reproducible and clearly discernible DNA fingerprint patterns were selected and then used to analyze the full set of $61 \mathrm{M}$. fructicola isolates from South Italy (Table 1).

By assuming that $M$. fructicola is haploid, like other Ascomycetes, each reproducible band in the selected ISSR patterns was considered as a putative locus with two alleles and visually scored for the presence (1) or absence (0) of the amplicon to obtain a binary matrix. An equal weight was given to all scored bands. A single multilocus profile was then constructed for each isolate and used to estimate linkage disequilibrium. The MultiLocus program v1.3b (Agapow and Burt 2001) was used to calculate the following parameters (Xu 2006): (i) the number of different genotypes; (ii) the genotypic diversity (GD; Simpson's index after correction for sample size); (iii) the index of association (IA); (iv) the proportion of compatible pairs of loci (PrCP). GD ranges from zero (all individuals with a same genotype) to one (all individuals with different genotypes). IA has an expected value of zero if the alleles at different loci are randomly associated with each other in the population, while significant associations between alleles at different loci would be expected in clonally reproducing populations.
PrCP approaches a value of 1 for no recombination. Briefly, two loci are compatible if it is possible to account for all the observed genotypes by mutations without inferring homoplasy or recombination; otherwise, the loci are incompatible. For example, for two loci with two alleles each, the loci are compatible if no more than three genotypes are observed; if all four genotypes are observed, these two loci are phylogenetically incompatible. Phylogenetic incompatibility suggests recombination in the population. IA and $\mathrm{PrCP}$ were calculated based on the clone-corrected data (McDonald 1997). The statistical significance of GD $\neq 1$, and the null hypotheses of full panmixia $(\mathrm{IA}=0)$ and full clonality $(\mathrm{PrCP}=$ 1) were evaluated against 1,000 randomized data sets.

Characterization of the MAT1 loci. Two isolates of opposite mating type per each species (bold in Table 1) were selected and used as references in the identification and characterization of the mating-type loci. The approach for the sequencing of the full-length loci was the primer-walking method (Sterky and Lundeberg 2000) that was previously used to sequence the MATl locus in B. cinerea (De Miccolis Angelini et al. 2016). Two rough draft genomes of the strains Mlax316 and Mfrg269, obtained by de novo assembly of next generation sequencing (NGS, Illumina) paired-end short reads $(2 \times 100 \mathrm{bp})$ and the assembled transcriptomes of M. fructicola, M. laxa, and M. fructigena (De Miccolis Angelini et al. 2018; data not published) were used as a starting point to identify and characterize MAT1 sequences in the Monilinia species.

tBLASTn was used to identify sequences with high similarity to the amino acid sequences encoded by MAT1-1-1 (AHX22632.1), MAT1-1-5 (AHX22633.1), MAT1-2-1 (AHX22634.1), MAT1-2-4 (AHX22635.1), recently renamed MAT1-2-10 (Wilken et al. 2017), and the flanking genes APN2 (EMR81656.1) and SLA2 (EMR81653.1) in $B$. cinerea, in our Monilinia genome and transcriptome databases. Based on the identified genomic and transcriptomic sequences, along with the partial MAT1-1-1 and MAT1-2-1 sequences previously obtained, we designed primer pairs to amplify by PCR overlapping genome sequences included between the APN2 and SLA2 genes and to sequence the entire MATI-1 and MATI-2 idiomorphs in each Monilinia species. The selected primer pairs, the size of amplified DNA fragments and PCR conditions are reported in Supplementary Table S1. PCR and sequencing were carried out as described above using 0.1 to $0.3 \mu \mathrm{g}$ of template DNA and cycling conditions as follows: 5 min at $95^{\circ} \mathrm{C}, 35$ cycles of $1 \mathrm{~min}$ at $95^{\circ} \mathrm{C}, 1 \mathrm{~min}$ at 58 to $65^{\circ} \mathrm{C}$ and 1 to $8 \mathrm{~min}$ at $72^{\circ} \mathrm{C}$, followed by a final extension of $7 \mathrm{~min}$ at $72^{\circ} \mathrm{C}$. The PCR products were visualized on gels and sequenced as described above. All partial MAT1 sequences obtained were aligned in SeqMan Pro and new primers designed for filling the gaps within the two idiomorphs of each Monilinia species.

The sequences were analyzed with the 'Start/Stop/ORF' procedure of the gene-finding program GeneQuest (Lasergene) by

TABLE 2. Primer pairs used to determine the mating type of Monilinia species ${ }^{\mathrm{a}}$

\begin{tabular}{|c|c|c|c|c|c|}
\hline Idiomorph & Primer pair & & Sequence $\left(5^{\prime}-3^{\prime}\right)$ & Annealing temperature $\left({ }^{\circ} \mathrm{C}\right)$ & Amplicon size (bp) \\
\hline \multirow[t]{3}{*}{ MAT1-1 } & $1 \mathrm{~A}$ & Fw & ATATGGTGCCTGGGAGATGC & 54 & 166 \\
\hline & & $\operatorname{Rev}$ & AGCCATCATACCAGTGGACC & & \\
\hline & 1B & Fw & CATTGCTTCCACTCAGAATGC & 54 & 182 \\
\hline \multirow[t]{10}{*}{ MATI-2 } & $2 \mathrm{~A}$ & Fw & TCCCACGTCCMGCTAATGAG & 54 & 246 \\
\hline & & Rev & AGCCTTCTTGTGAGCTTCCT & & \\
\hline & 2B & Fw & CTCAAGCCAAAGATCCCACG & 54 & 223 \\
\hline & & Rev & RATCTTGTACTTCARRCGCC & & \\
\hline & 2D & Fw & TCAAGGAAAGCTTATCCAGGGT & 60 & 204 \\
\hline & & Rev & AGCCTTCTTGTGAGCTTCCT & & \\
\hline & $2 \mathrm{E}$ & $\mathrm{FW}$ & AGCTTCAATTATCGCTGGCA & 60 & 158 \\
\hline & & Rev & AGCCTTCTTGTGAGCTTCCT & & \\
\hline & $2 \mathrm{~F}$ & $\mathrm{FW}$ & CCCCGCTATGATTTCAATTTTCT & 60 & 122 \\
\hline & & Rev & TTCCTTCAAAACATCGGCGC & & \\
\hline
\end{tabular}

a Primer pairs used for assessing the mating type of field isolates are in bold. 
using the Borodovsky method to predict the open reading frames (ORFs) and putative splicing sites. BLASTx analysis suggested the gene structure and the presence of introns and exons. SeqBuilder (Lasergene) was used to make a graphical representation of the structural organization of the mating genes.

BLASTn was used for the identification of unique idiomorphic sequences in the three Monilinia species and the pairwise comparison of the MAT1 genes and intergenic regions. Multiple sequence alignments of the MAT1-encoded proteins in the Monilinia spp. and the homologous proteins in fungi belonging to the order Helotiales were carried out using ClustalW and phylogenetic trees generated using MEGA7: Molecular Evolutionary Genetics Analysis version 7.0 (Kumar et al. 2016).

Transcript analysis of MAT1 genes. Transcript identification and quantification of the expression of MAT1 genes were assessed by high-throughput mRNA sequencing (RNA-Seq) from the isolates used for the molecular characterization of MAT1 loci (bold in Table 1). Total RNA was extracted from about $100 \mathrm{mg}$ of mycelium or germinating conidia by using RNeasy Plant Mini kit (QIAGEN, Milan, Italy), according to the manufacturer's instructions, and used to prepare cDNA libraries with TruSeq RNA Sample Preparation Kit v2 (Illumina, Inc., San Diego, CA). Sequencing was carried out on an Illumina HiScanSQ platform using TruSeq SBS kit v3 (Illumina, Inc.) to obtain paired-end reads, each $92 \mathrm{nt}$ in length. After removing indexed adapters, reads were filtered for quality score $(\mathrm{QS}) \geq 30$ using CASAVA v1.8 software (Illumina, Inc.) and aligned on the assembled MAT1 loci, quantified and visualized using SeqMan NGen (Lasergene) with default parameters for the option "classic assembler". Detection of reads spanning across putative splice junctions was used to assess prediction accuracy for protein coding gene structures and annotate transcribed sequences within the MAT1 loci in Monilinia species. Gene expression was measured as reads per kilobase per million mapped reads (Trapnell et al. 2010).

\section{RESULTS}

Molecular assay for mating type. Four primer pairs, designed on conserved regions of the mating-type genes of $B$. cinerea and S. sclerotiorum, were preliminary tested on a pool of Monilinia isolates. Single isolates produced amplicons with only one of the primer pairs: the pair 1B, designed on the MAT1-1-1 gene, yielded a single 182-bp amplicon from genomic DNA of the isolates Mfrc123, Mfrc150, Mfrc261, Mfrc159; Mlax34, Mlax316, Mlax509, Mlax292; Mfrg342, Mfrg343, Mfrg269, Mfrg340, Mfrg341, and Mfrg510; the pair 2A, designed on the MAT1-2-1 gene, yielded a single 246-bp amplicon from genomic DNA of the isolates Mfrc78, Mfrc534; Mlax297, Mlax302, Mlax346, and Mfrg344. PCR products from one isolate per species and mating type (Mfrc159, Mfrc534, Mlax316, Mlax297, Mfrg340, and Mfrg344) were sequenced and analyzed by BLAST search to confirm their nature. The 182-bp products showed 74 to $76 \%$ identity with the MAT1-1 idiomorph (KF944385.1) and the 246-bp products showed 82 to $86 \%$ identity with the MAT1-2 idiomorph (KF944386.1) of B. cinerea. The primer pair 2C designed on the 246-bp sequences of the strains Mlax297 and Mfrc83, yielding a 150-bp amplicon (Table 2), improved the sensitivity and specificity of the assay for the MAT1-2 idiomorph compared with the pair 2A and was then used for further analysis.

The mating type of 155 isolates (125 of M. fructicola, 22 of $M$. laxa, and 8 of $M$. fructigena) was assessed by PCR (Supplementary Fig. S1). Both mating types were detected in each Monilinia species and a total of 77 isolates were MAT1-1 and 78 isolates were MAT1-2. In detail, among Italian M. fructicola isolates, 34 were identified as MAT1-1 and 27 as MAT1-2. Both mating types were also generally detected among $M$. fructicola isolates from other countries except those represented by only few isolates. All the isolates from Greece (four isolates), China (four), Georgia (two), and New York (two) were MAT1-2, while the only one from Australia was MAT1-1. M. laxa samples included 10 MAT1-1 and 12 MAT1-2 isolates. Finally, six MATl-1 and two MATl-2 isolates constituted the $M$. fructigena samples (Table 3). The two mating types were in ratios statistically close to $1: 1$ in each of the three species $\left(\chi^{2}\right.$ values were 0.04 for $M$. fructicola, 0.09 for M. laxa, and 1.0 for $M$. fructigena; $\chi^{2}=3.84$ for $P=0.05$ ).

ISSR profiling and linkage disequilibrium analysis in M. fructicola. Eight of the 13 ISSR primers (i.e., Mf-2, Mf-3, Mf5, Mf-8, Mf-11, M-13-Mf, SRR-2, and SRR-5) used on the whole set of 61 isolates produced reproducible polymorphic bands. Each of the selected primers amplified from 5 (Mf-5) to 10 (Mf-2 and SSR-2) bands per isolate which varied in size from 200 to 2,500 bp. Of the 54 amplified bands, 29 were monomorphic across all isolates and 25 were polymorphic with an average of three polymorphic bands per primer (Supplementary Fig. S2). Forty-nine genotypes were identified among the 61 isolates. GD was 0.992 , slightly but significantly $(P<0.001)$ lower than the value of one expected for full random mating. The observed IA was 0.474 , significantly $(P<$ $0.001)$ higher than the mean IA $(0.003)$ of the random data set, so that the null hypothesis of complete panmixia was rejected. The PrCP value was $0.899(P=0.015)$ and hence the null hypothesis of full clonality was also rejected. When the IA and the PrCP results were combined, there was some evidence for recombination (most likely by means of sexual reproduction) against a background of predominantly asexual reproduction.

Characterization of the MAT1 locus. tBLASTn using amino acid (aa) sequences from $B$. cinerea identified putative $A P N 2$, MAT1-1-1, MAT1-1-5, and SLA2 genes in genomic contigs of the

TABLE 3. Distribution of the MAT1-1 and MAT1-2 idiomorphs in Monilinia species according to their origin

\begin{tabular}{|c|c|c|c|c|c|c|c|}
\hline \multirow[b]{2}{*}{ Origin } & \multirow[b]{2}{*}{ Country/state } & \multicolumn{2}{|c|}{ M. fructicola } & \multicolumn{2}{|c|}{ M. laxa } & \multicolumn{2}{|c|}{ M. fructigena } \\
\hline & & MAT1-1 & MAT1-2 & MAT1-1 & MAT1-2 & MAT1-1 & MAT1-2 \\
\hline \multirow[t]{5}{*}{ Europe } & Italy & 34 & 27 & 10 & 12 & 5 & 2 \\
\hline & France & 2 & 3 & & & & \\
\hline & Serbia & 3 & 2 & & & & \\
\hline & Spain & 7 & 3 & & & & \\
\hline & The Netherlands & & & & & 1 & \\
\hline \multirow{4}{*}{ USA } & New York & & 2 & & & & \\
\hline & South Carolina & 3 & 2 & & & & \\
\hline & Virginia & 1 & 1 & & & & \\
\hline & Unknown & 2 & 2 & & & & \\
\hline \multirow[t]{2}{*}{ Oceania } & Australia & 1 & & & & & \\
\hline & New Zealand & 4 & 2 & & & & \\
\hline Asia & China & & 4 & & & & \\
\hline
\end{tabular}


strains Mlax316 (55,736 bp) and Mfrg269 (36,171 bp). It was not possible to detect the MAT1-2 genes because both the strains were MAT1-1. The percent identity values of amino acid sequences were up to $76 \%$ (M. laxa) and 75\% (M. fructigena) for the MAT1-1-1 alpha-box protein, $77 \%$ for the MAT1-1-5 putative protein, $74 \%$ (M. laxa), and $77 \%$ (M. fructigena) for the APN2 and up to $93 \%$ for the SLA2 proteins (E-values $\leq 1 \mathrm{e}-85$ ). Similarly, tBLASTn identified in the transcriptomes of each species partial or complete (119 to 2,010 bp) transcript sequences for the $M A T 1$-specific genes, with the only exceptions of MAT1-2-10 in M. laxa and M. fructigena, and the flanking APN2 and SLA2 genes (E-values $\leq 5 \mathrm{e}-23$ ).

Using the primer pairs designed on the identified genomic sequences, we obtained 7,041 (M. laxa) and 6,933 (M. fructigena) nucleotide sequences encompassing the entire MAT1-1 idiomorphs and adjacent regions. The assembled sequences were $99 \%$ identical to those obtained by NGS assembly. We supposed a similar structure of the MAT1-1 locus also in M. fructicola, and hence, we designed primers on the available transcript sequences of the MATI-1 and the flanking APN2 and SLA2 genes in M. fructicola which were successfully used to amplify and sequence overlapping regions of the locus. The assembled MAT1-1 sequence of $M$. fructicola was 7,979 bp in length.

The entire MAT1-2 idiomorphs and adjacent regions of the three species were obtained by designing PCR primers on transcript sequences of the MAT1-2-1 and MAT1-2-10 genes and the APN2 and SLA2 gene sequences from the reconstructed MAT1-1 idiomorphs. The assembled sequences were 7,135 bp (M. laxa), 7,667 bp (M. fructicola), and 8,050 bp (M. fructigena) in length (Fig. 1).

The MAT1-1 idiomorphs include two ORFs identified by both GeneQuest and BLASTx analyses. The predicted MAT1-1-1 genes are $1,137 \mathrm{bp}$ (M. fructicola) or 1,132 bp (M. laxa and M. fructigena) in length, with two exons ( 259 and $824 \mathrm{bp}$ ), separated by an intron of $54 \mathrm{bp}$ (M. fructicola) or 49 bp (M. laxa and M. fructigena). The encoded proteins (360 aa), containing the conserved alpha-box domain (pfam04769), are 96 to $98 \%$ identical in the three species and BLASTp search showed 73 to $74 \%$ aa identity with the homologous Botrytis elliptica protein (AKC57287.1). The predicted MAT1-1-5 genes have the same structure in the three species. They are 1,304 bp in length, contain four exons $(277,548,27$, and $279 \mathrm{bp}$ ) interrupted by three short introns $(49,65$, and $59 \mathrm{bp})$. The encoded proteins (376 aa), with no putative conserved domain, showed 93 to $98 \%$ aa identity in the three species and the highest amino acid identity (70\%) with the homologous Sclerotinia minor protein (AHA49902.1) in BLASTp search.

The MAT1-2 idiomorphs include two ORFs. The predicted MAT1-2-1 genes have the same structure in the three species. They are $1,176 \mathrm{bp}$ in length and contain two introns (58 and $53 \mathrm{bp}$ ) and three exons (410, 371, and $284 \mathrm{bp}$ ). The encoded proteins (354 aa), containing the conserved HMG-box domain (cd00084), are 91 to 95\% identical in the three species and BLASTp search showed the highest amino acid identity (70\%) with the homologous Sclerotinia borealis F-4128 protein (ESZ90540.1). The predicted MAT1-2-10 genes are $957 \mathrm{bp}$ in length and contain two introns (both of $48 \mathrm{bp}$ ) and three exons (434, 239 , and $188 \mathrm{bp}$ ). The encoded proteins (286 aa), with no putative conserved domain, showed 90 to $92 \%$ aa identity in the three species and the highest amino acid identity ( 56 to $58 \%$ ) with the homologous S. sclerotiorum protein (AGB05588.1).

The sequences of the MAT1 locus and their respective flanking regions in the MAT1-1 and the MAT1-2 strains of M. laxa, $M$. fructigena, and $M$. fructicola have been deposited in GenBank database under accession numbers MG182161 (MAT1-1, Mlax316), MG182162 (MAT1-1, Mfrg269), MG182163 (MAT1-1, Mfrc123), MG182164 (MAT1-2, Mlax297), MG182165 (MAT1-2, Mfrg344), and MG182166 (MAT1-2, Mfrc78).

The assembled MAT1 locus sequences in each species were aligned using BLASTn. In both M. laxa and M. fructigena, the 5' $(1,200 \mathrm{bp})$ and the $3^{\prime}(1,600 \mathrm{bp})$ termini showed $99 \%$ identity. In M. fructicola, the $5^{\prime}(1,310 \mathrm{bp})$ and the $3^{\prime}$ (2,121 bp) termini showed
97 and $95 \%$ identity, respectively. Highly divergent idiomorphic sequences of different sizes were hence identified. The MAT1-21 genes extend for $47 \mathrm{bp} \mathrm{(M.} \mathrm{laxa)} \mathrm{or} 54 \mathrm{bp}$ (M. fructicola) in the 5' flanking region and then a homologous dMAT1-2-1 (87 to $94 \%$ identity, E-value $\leq 3 \mathrm{e}-15$ ) was detected in the opposite idiomorph. In addition, other dMAT1-2-1 sequences (203 bp, M. fructicola; $249 \mathrm{bp}$, M. laxa; $258 \mathrm{bp}$, M. fructigena; 72 to $76 \%$ identity, E-values $\leq 1 \mathrm{e}-33$ ) were detected in the unique MAT1-1 sequences. In the three species, two dMAT1-1-1 sequences (290 to 299 bp, 73 to $77 \%$ identity, E-values $\leq 1 \mathrm{e}-46$; 170 to $225 \mathrm{bp}, 79$ to $83 \%$ identity, E-values $\leq 1 \mathrm{e}-46$ ) were detected in the unique MAT1-2 sequences. In $M$. fructicola the second fragment corresponds to the MAT1-1-1 gene extension in the 3' flanking region. Furthermore, the internal dMAT1-1-1 fragments (290 to $299 \mathrm{bp}$ ) showed similarity (E-values $\leq 1 \mathrm{e}-44)$ to the direct or inverted repeats (230 to $250 \mathrm{bp}$ ) responsible for intramolecular recombination events in homothallic Sclerotinia species (Chitrampalam et al. 2013; Xu et al. 2016).

The two idiomorphs showed high sequence identity in the intergenic regions 5' IGR-1 (97 to 99\%) and 3' IGR-3 (90 to 97\%), while, as expected, it was lower (46 to $47 \%$ ) in the internal IGR-2. By comparing the three species, IGR-1 and IGR-3 showed a lower sequence identity (69 to 89\%; 67 to $91 \%$ ) than IGR-2 (91 to 94\%), while comparing the mating types, the identity of IGR-1 was lower in MAT1-1 (69 to 72\%) than in MAT1-2 (82 to 89\%). In all pairwise comparisons between species, $M$. laxa and $M$. fructigena IGRs showed higher sequence identity (80 to $94 \%$ ) with each other than with $M$. fructicola (67 to $92 \%$; 68 to $93 \%$, respectively).

Phylogenetic analysis of the four MAT1-specific protein sequences of $M$. fructicola, $M$. fructigena, and M. laxa with those of fungi belonging to the order Helotiales available in databank yielded very similar results (Fig. 2). The three Monilinia species grouped together in a clade close to those formed by the other fungi belonging to Sclerotiniaceae, B. cinerea and B. elliptica, and most of the Sclerotinia species. The MAT1-2-10 proteins of Monilinia spp. were more similar to those of Sclerotinia spp. than Botrytis spp. The clade of Rutstroemiaceae, which grouped also Sclerotinia homoeocarpa, and at a higher degree, the clade of the Helotiaceae, including Glarea lozoyensis and Hymenoscyphus spp., were evolutionary more distant. Low rates of amino acid substitutions were recorded in the MAT1 genes of M. fructicola, M. laxa, and M. fructigena, with M. laxa and M. fructigena more like each other than M. fructicola.

Expression of MAT1 genes. We estimated gene expression and assessed prediction accuracy for the MAT1 genes by mapping RNA-Seq reads (36.4 to 37.3 million for the MAT1-1 idiomorphs; 32.1 to 36.2 million from the MAT1-2) onto the reconstructed genomic sequences of the two idiomorphs in each species. The expression levels of the mating-type genes were generally low and could not be detected for the MAT1-2-10 gene in M. fructigena (Fig. $3)$. As expected, reads from single isolates mapped exclusively either on the MAT1-1 or MAT1-2 idiomorphic sequences, according to the own mating type.

The reads covered $98 \%$ of the MAT1-1-1 transcript sequence in M. fructicola, $88.5 \%$ in M. laxa, and $77.9 \%$ in M. fructigena. It was not possible to confirm the predicted splicing site because of low read depth. However, two unpredicted splicing events originated by new candidate introns both with antisense orientation were observed at the $3^{\prime}$ terminus ( $50 \mathrm{bp}$, nucleotide position 5561 to $5610)$ and downstream (68 bp, nucleotide position 5808 to 5975) the MAT1-1-1 gene in M. fructicola (MG182163). The mapped reads covered the entire length of the MAT1-1-5 transcript in M. laxa, including the predicted start and stop and three splice sites, validating intron predictions. Partial coverages of the transcripts were obtained in $M$. fructicola (72.4\%) and M. fructigena (30.2\%) due to low expression levels, but the three predicted splice sites were confirmed in M. fructicola. Expression level of MAT1-2-1 was higher in M. fructicola (full coverage) than in M. laxa (95\%) and M. fructigena 
(78\%). The two predicted splice sites were confirmed in $M$. fructicola and M. laxa; in M. fructigena only the position of the 58-bp intron within the HMG-box domain could be confirmed. Novel candidate introns of $119 \mathrm{bp}$ (from 1642 to 1760) and $53 \mathrm{bp}$ (from 2578 to 2630), originating from antisense-oriented alternative transcripts, were observed in M. laxa (MG182164). The MAT1-2-10 transcript sequence was completely covered although at low read depth in M. fructicola, partially covered in M. laxa (78.5\%), and no mapped reads were obtained for $M$. fructigena. Only the splice junctions at the $5^{\prime}$ introns (48 bp) in M. laxa and M. fructicola were confirmed.
Transcription of a region (289 bp) of the MAT1-2 idiomorph, including the 170-bp $d M A T 1-1-1$ sequence and near-identical flanking region downstream the MAT1-2-10 gene, was detected in $M$. fructicola. Moreover, a transcribed region $(1,036 \mathrm{bp})$ of the MAT1-1 idiomorph, including the 249-bp dMAT1-2-1 sequence and extending for $278 \mathrm{bp}$ in the $5^{\prime}$ flanking region, was detected in M. laxa (MG182161). It contained two putative introns of $53 \mathrm{bp}$ (from 1,457 to 1,405 ) and $64 \mathrm{bp}$ (from 2,103 to 2,040) in the antisense orientation. Only few reads mapped on the corresponding regions in the MAT1-1 idiomorphs of M. fructicola and M. fructigena.

(a)

\section{M. fructicola}

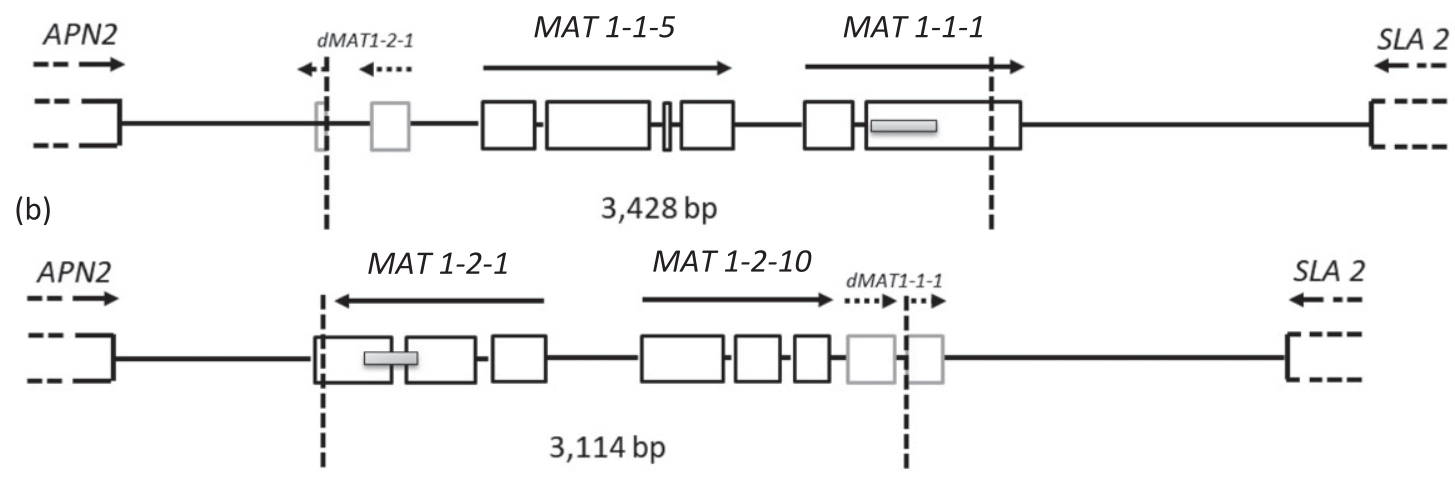

(a)

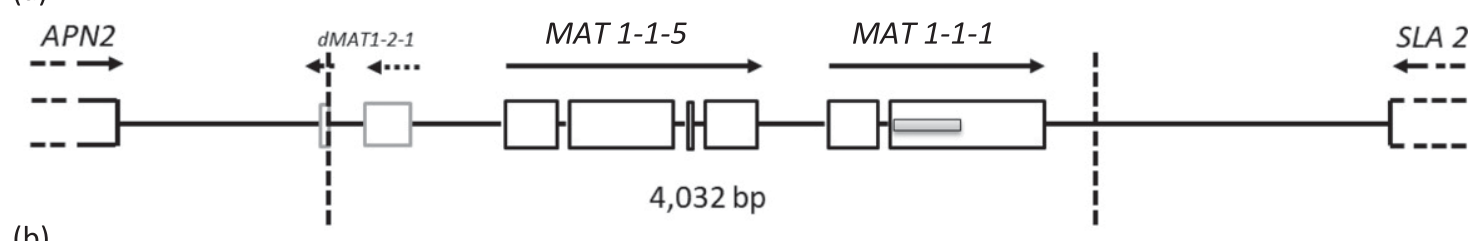

(b)

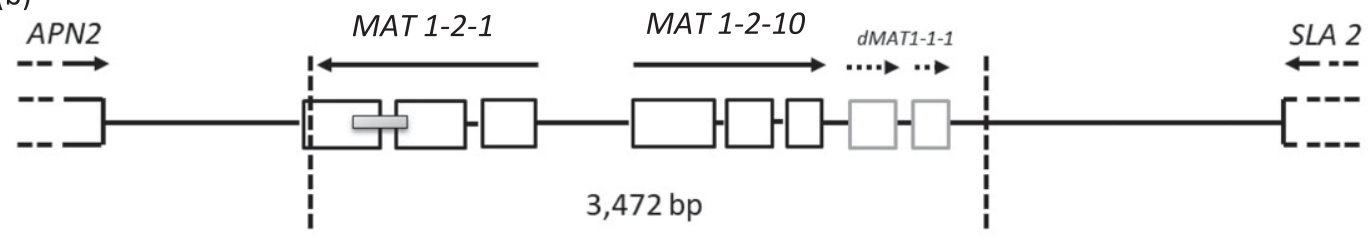

(a)

\section{M. fructigena}

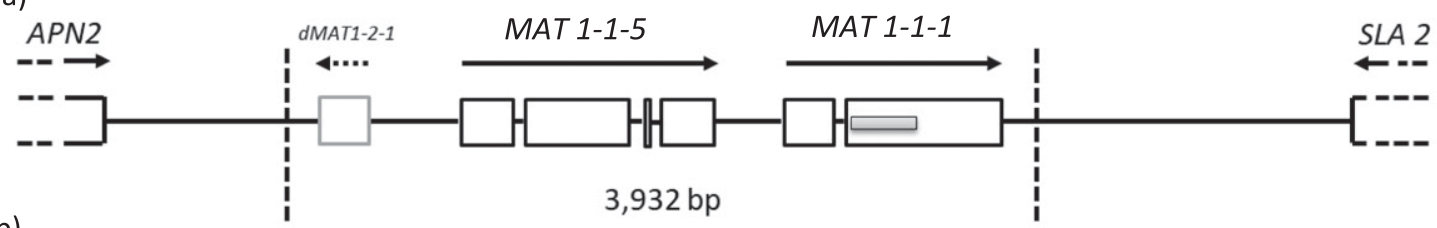

(b)

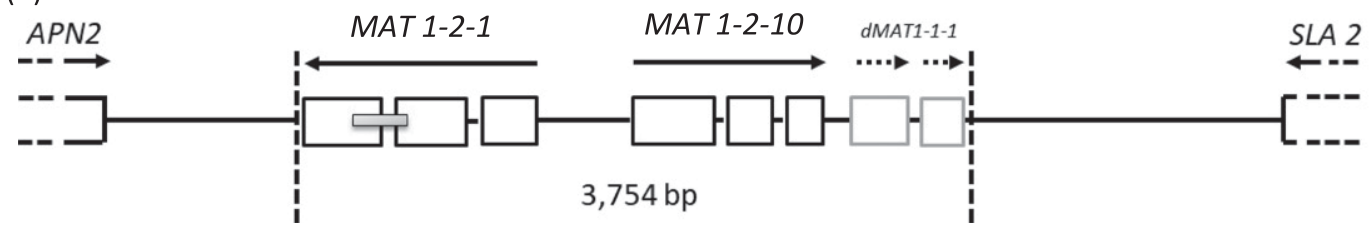

Fig. 1. Structures of the mating-type (MAT1) loci in the MAT1-1 (a) and MAT1-2 (b) idiomorphs of Monilinia fructicola, M. laxa, and M. fructigena. Solid boxes represent the coding region of the predicted genes interrupted by introns. Internal gray box within the MATI-1-1 and MAT1-2-1 genes are the conserved alpha-box and HMG-box domains, respectively. Arrows indicate orientation of coding sequences. Sizes of the unique sequences of each idiomorph (delimited by dotted lines) are reported. 


\section{DISCUSSION}

Sexual reproduction, when occurring, is a major source of genetic variation in fungal populations and may create novel recombinant genotypes with altered virulence or increased fitness in new ecological niches (Heitman 2006; Ni et al. 2011). The mating systems are diverse in the family Sclerotiniaceae, which include both homothallic and heterothallic species. For instance, $B$. cinerea and B. elliptica display a bipolar heterothallism, $S$. minor and $S$. sclerotiorum display homothallism, while Sclerotinia trifoliorum and $S$. homoeocarpa include either homothallic or heterothallic isolates. In heterothallic species, the MAT1-1 or the MAT1-2 idiomorphs are singly carried by self-sterile individuals, while in homothallic species they are closely linked end-to-end at a single MAT1 locus in self-fertile individuals (Amselem et al. 2011; Chitrampalam and Pryor 2015; De Miccolis Angelini et al. 2016; Putman et al. 2015; Terhem et al. 2015; Xu et al. 2016). The mating system governing the sexuality in the genus Monilinia was largely unexplored and no information was available for M. laxa and M. fructigena. M. fructicola was initially reported to be homothallic (Ezekiel 1924; Harada 1977), but other studies suggested that it is capable of outcrossing (Sharvell and Chen 1943; Sonoda et al. 1982; Thind and Keitt 1949) and this was finally demonstrated by segregation of mycelial incompatibility and fungicide resistance genes in ascospores progeny (Free et al. 1996). A search of conserved sequences by alignments of the MATI loci in $B$. cinerea and S. sclerotiorum allowed us to design a PCR assay based on idiomorphspecific primers for rapid mating-type assessment in Monilinia isolates. The molecular assay was applied to 61 M. fructicola, $22 \mathrm{M}$. laxa, and $8 \mathrm{M}$. fructigena isolates from 9 districts in South Italy and 64 $M$. fructicola isolates from 14 geographic areas, including other European countries, the United States, Australia, New Zealand, and China. Each isolate of the three Monilinia species carried only one
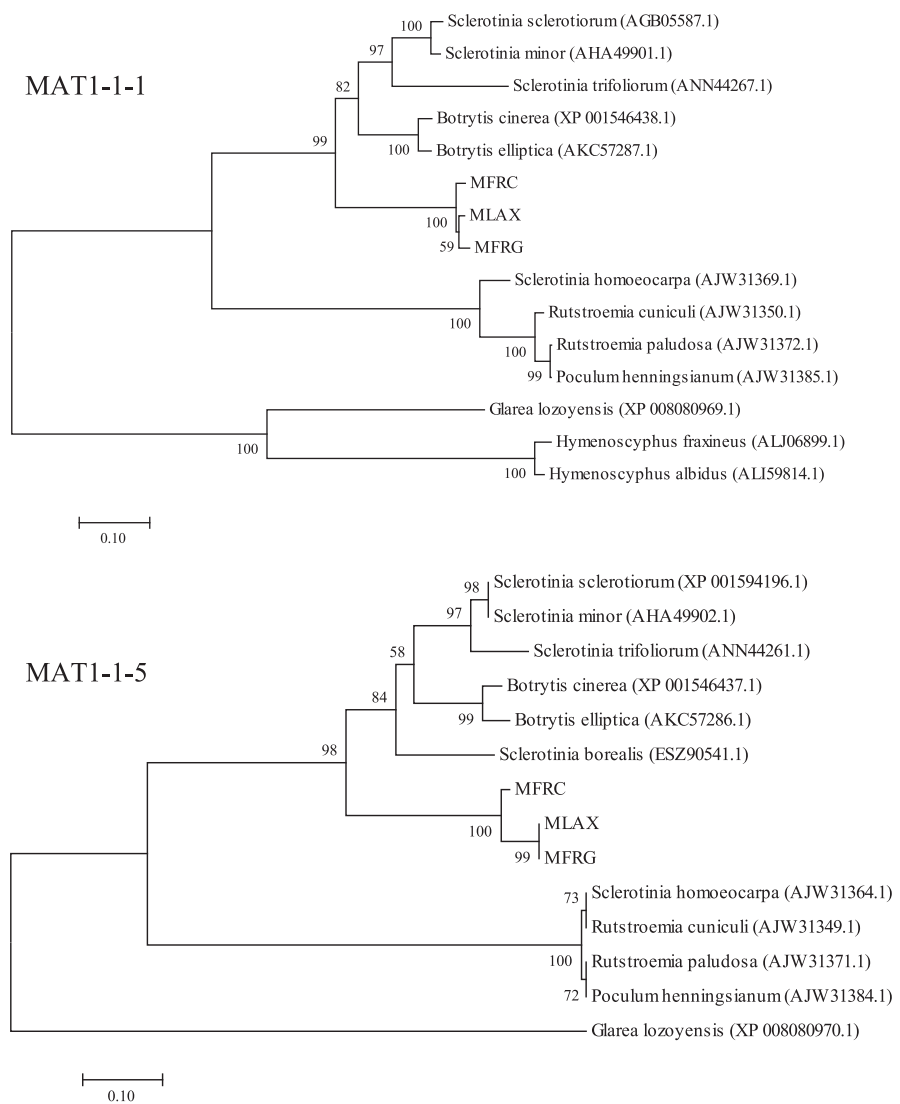

of the two alternative idiomorphs at the MAT1 locus. Hence, we firstly showed at molecular level that M. fructicola, M. laxa, and $M$. fructigena have a bipolar heterothallic mating system, typical of other self-incompatible Ascomycetes. Both mating types were represented among the isolates from most countries, except those with small-sized fungal samples. Overall, the two mating types were in balanced distribution in the populations of the three Monilinia species and this indicates the absence of genetic barriers to the occurrence of sexual reproduction and the potential for outcrossing in most of the geographic areas in which the pathogens are present.

As to $M$. fructicola, a quarantine pathogen first reported in Europe in 2001 (OEPP/EPPO 2002) and in 2009 in North Italy (Pellegrino et al. 2009), the results of the present monitoring

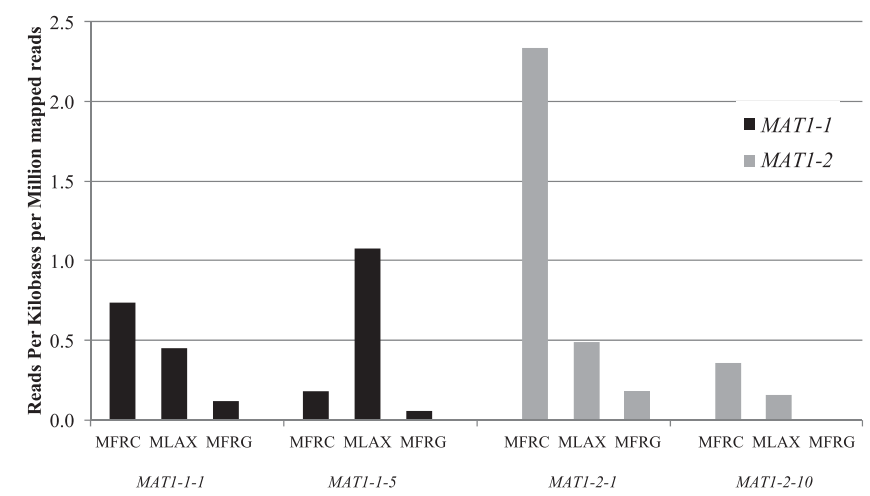

Fig. 3. Expression levels of the MAT1 genes in MAT1-1 and MAT1-2 isolates of Monilinia fructicola (MFRC), M. laxa (MLAX), and M. fructigena (MFRG).
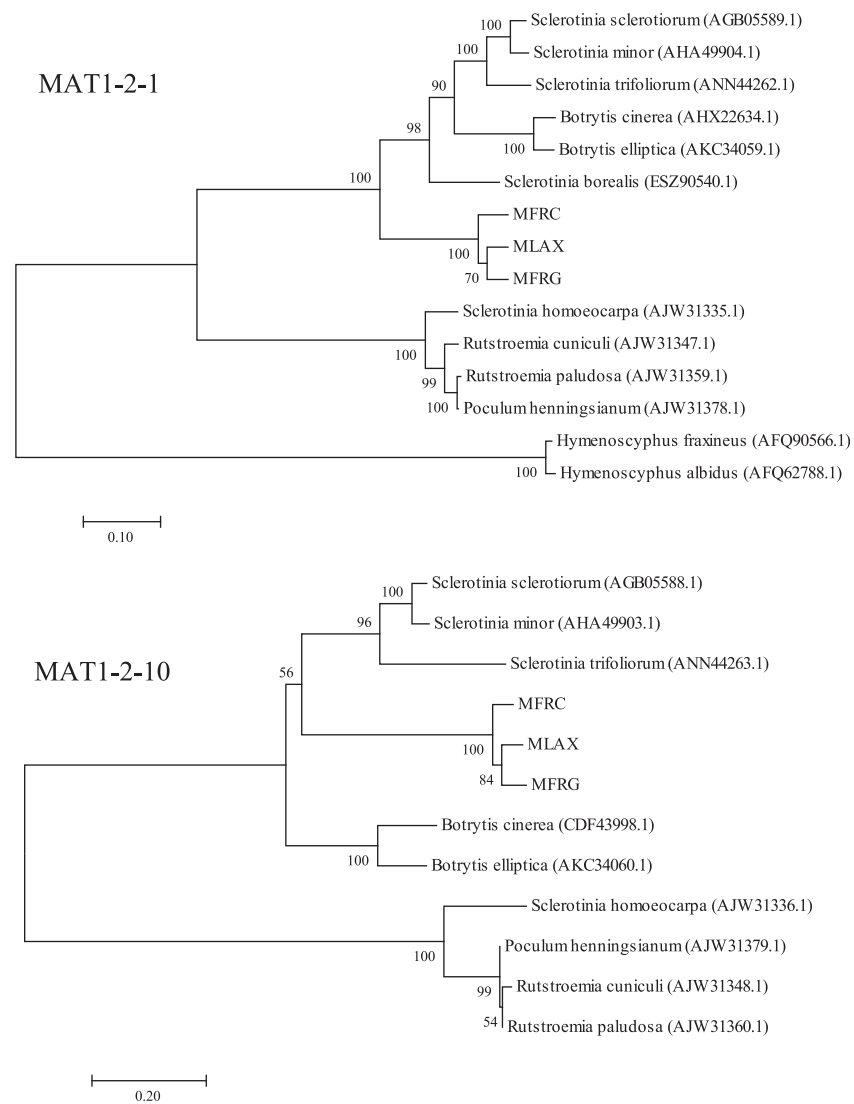

Fig. 2. Evolutionary relationships of the mating-type-specific proteins of Monilinia fructicola (MFRC), M. laxa (MLAX), and M. fructigena (MFRG) and other fungi belonging to Helotiales. The tree was inferred using the neighbor-joining method and the evolutionary distances (number of amino acid substitutions) were computed using the Poisson correction method eliminating all positions containing gaps and missing data. Bootstrap test was carried out with 1,000 replicates. 
demonstrated that both idiomorphs were introduced and established in the continent as well as in Italy. However, there are no reports of apothecia findings in the field in Europe in contrast to the common occurrence of sexual reproduction and apothecia differentiation in the United States (Michailides et al. 2007). For this reason, the genetic structure of $M$. fructicola population in Italy was investigated by using ISSR markers. Forty-nine genotypes were found in 61 tested isolates.

On the ground of the statistically significant values of GD (0.992), IA (0.474), and PrCP (0.899), there is some evidence for recombination (most likely by means of sexual reproduction) in a prevalently clonal population, like reported in other European countries (De Cal et al. 2014; Jänsch et al. 2012; Villarino et al. 2012). Hence, we can suppose that sexual reproduction potentially occurs at low frequency although other genetic sources of variation, such as heterokaryosis and parasexuality, could also underlie recombination. The predominant clonality of the population and the apparently limited occurrence of the sexual reproduction might be due to different reasons: (i) the prodigious conidial production in $M$. fructicola well timed to initiate infection in susceptible plant tissues; (ii) the hot and dry climatic conditions of South Italy, which are generally not inducive to apothecia differentiation; and (iii) crop management factors, such as removal of infected fruits by growers or destruction and interring of mummified fruits during soil tillage (Holtz et al. 1998; Michailides et al. 2007; Villarino et al. 2012).

Studies on genetic variation and IA analyses revealed comparable results for the closely related species $S$. sclerotiorum and B. cinerea. S. sclerotiorum populations on different crops in the United States showed prevalent clonality and some evidence of recombination (Aldrich-Wolfe et al. 2015; Dunn et al. 2017). A high level of genetic diversity but nonrandom mating was observed in $B$. cinerea populations in California (Ma and Michailides 2005) and South Africa (Wessels et al. 2016), suggesting the absence or infrequent sexual reproduction, that was instead supposed to occur in other areas on various hosts, like Hungarian vineyards (Váczy et al. 2008).

By combining high-throughput sequencing data with targeted PCRs and sequencing using the primer walking approach, the fulllength sequences of the MAT1 loci from the three Monilinia species were determined. The genetic organization of the loci was very similar in the three Monilinia species, in terms of gene content, synteny and intron number and positions, and appeared highly similar to those of the closely related heterothallic $B$. cinerea and B. elliptica (Amselem et al. 2011; De Miccolis Angelini et al. 2016; Terhem et al. 2015). The Monilinia MAT1 loci are flanked by APN2 and SLA2 genes and have typical features of the heterothallic Pezizomycotina, in which the MAT1-1 idiomorph contains a gene, namely MAT1-1-1, encoding a protein with a conserved alpha-box domain, while the MAT1-2 contains a gene, the MAT1-2-1, encoding a protein with a conserved HMG domain (Debuchy et al. 2010). In addition, the two idiomorphs contain the MAT1-1-5 or the MAT1-2-10 genes, both encoding predicted proteins with no conserved functional domains.

Fragments of the MAT1-1-1 gene (dMAT1-1-1) were detected at the $3^{\prime}$ end of the MAT1-2 idiomorphs and the $3^{\prime}$ end of the MAT1-2-1 gene (dMAT1-2-1) was detected at the $5^{\prime}$ end of the MAT1-1 idiomorphs. A duplicated short fragment of $d M A T 1-2-1$ was also detected bordering the near-identical 5' flanking region of MAT1-1 idiomorphs in M. fructicola and M. laxa. Homologous sequences of the opposite idiomorph at similar positions have been reported in the heterothallic B. cinerea, B. elliptica, and S. homoeocarpa and are believed nonfunctional truncated $M A T 1$ genes. The presence of fragments of mating-type genes in the opposite MATl idiomorph suggests that the heterothallic MAT1-1 and MAT1-2 loci evolved from an ancestral homothallic locus by multiple recombination and deletion events with loss of MAT1-specific sequences (Amselem et al. 2011; Rodenburg et al. 2018). This evolutionary scenario had been proposed for other Ascomycetes showing similar features at the MAT1 locus (Paoletti et al. 2005; Tsui et al. 2013). More recently, different hypotheses have been proposed on the possible evolution of homothallic Sclerotinia species from heterothallic ancestors that are consistent with the structure of newly characterized MATI loci in Sclerotiniaceae and are more parsimonious involving a lower number of evolutionary changes. According to $\mathrm{Xu}$ et al. (2016), indeed, a single structural rearrangement, consisting of a simple insertion of the MAT1-2 idiomorph into the MAT1-1 idiomorph at the MAT1 locus in a heterothallic ancestor with a locus like those of $B$. cinerea, B. elliptica, and Monilinia species, could be the origin of a homothallic locus, like in the Inv+ MAT alleles in S. minor and S. sclerotiorum and in the $\mathrm{L}$ allele in $S$. trifoliorum.

A low genetic diversity is expected in chromosomal regions carrying the $M A T$ idiomorphs because recombination is supposed to be suppressed and rare at the MAT1 locus in Ascomycetes (Idnurm 2011). Mating-type gene sequences have been frequently used as markers in phylogenetic studies or to establish species boundaries in different genera of Ascomycetes (Lopes et al. 2017; O'Donnell et al. 2004), although several authors found them of limited utility (Geng et al. 2014; Strandberg et al. 2010). The three Monilinia species showed high similarity of the sequences of genes and intergenic regions within the MAT1-1 and MAT1-2 idiomorphs while it was lower in the bordering regions. Phylogenetic analysis of the four MAT1-specific protein sequences of $M$. fructicola, M. fructigena, and M. laxa within the order Helotiales yielded quite comparable results and the three Monilinia species constituted a clade close to those formed by the other fungi belonging to Sclerotiniaceae, i.e., B. cinerea and B. elliptica, and most of the Sclerotinia species. The MAT1-2-10 proteins of Monilinia spp., different from the others, were more similar to those of Sclerotinia spp. than to Botrytis spp. M. laxa and M. fructigena were more like each other than M. fructicola. This is consistent with the evolutionary hypothesis of the Monilinia species based on phylogenetic analysis of coding (G3PDH and TUB2) and noncoding rDNA (ITS) sequences. $M$. fructicola may have evolved earlier than other species, which were polyphyletic and shared a single common ancestor with $M$. fructicola. $M$. mumecola appears to be a direct descendant of M. laxa and M. fructigena may have evolved from M. yunnanensis (Hu et al. 2011; Yin et al. 2015). In our analysis, the clades made up by Rutstroemiaceae and Helotiaceae were evolutionary more distant. As previously reported, S. homoeocarpa, which does not produce a true sclerotium like the other Sclerotiniaceae but an indeterminate plate-like substratal stroma, was more closely related to Rutstroemiaceae (Putman et al. 2015).

Transcriptome sequencing data from Monilinia isolates of opposite mating types confirmed the accuracy of mating-type gene prediction at intron-exon boundaries and demonstrated that the MAT1 genes are expressed, although at low levels, during vegetative growth (mycelium and germinating conidia). Constitutive expression of the mating-type genes has already been reported in B. cinerea (De Miccolis Angelini et al. 2016), Sclerotinia spp. (Doughan and Rollins 2016; Xu et al. 2016), and other unrelated fungi (Bidard et al. 2011; Ferreira et al. 1996). Genes at the matingtype locus typically control sexual reproduction and are required during fruiting-body development (Pöggeler et al. 2006; Doughan and Rollins 2016). MAT1-1-1 and MAT1-2-1 are master regulatory conserved genes with an essential role in the mating process. They are thought to act as transcriptional regulators of pheromone signaling and are responsible for distinct patterns of gene expression in sexually compatible mating types (Bidard et al. 2011; Debuchy and Turgeon 2006; Debuchy et al. 2010; Pöggeler et al. 2006). Gene deletion of MAT1-1-5 and MAT1-2-10 in knockout mutants of $B$. cinerea and $S$. sclerotiorum proved that these two genes play a role in apothecial disk development (Doughan and Rollins 2016; Rodenburg et al. 2018). Nevertheless, the nature and roles of these additional mating-type genes, not conserved in filamentous fungi, in sexual reproduction remain to be 
investigated in Monilinia. The expression of all the MAT1 genes in mating noninducing conditions corroborates the hypothesis that they may have other functions besides sexuality with multiple pleiotropic effects on several phenotypic traits, such as vegetative growth, asexual sporulation, and pathogenicity. For instance, lossof-function $M A T 1$ gene mutants of $S$. sclerotiorum produced defects in secondary sexual characters including lower numbers of spermatia and altered expression of pheromone precursor and receptor genes (Doughan and Rollins 2016). Lack of the MAT1-2 genes in self-sterile isolates results in ascospores of a smaller size in S. trifoliorum (Xu et al. 2016) or in reduced fitness and pathogenicity in Ceratocystis albifundus (Lee et al. 2015). In Penicillium chrysogenum, the MAT1-1-1 transcription factor also participates in key biological processes such as regulation of asexual development and morphogenesis, as well as amino acid, iron, and secondary metabolism (Becker et al. 2015). The mating-type genes control conidial number and size in Ulocladium botrytis (Wang et al. 2017). Virulence genes were also included among targets of mating-type transcription factors in Cryptococcus neoformans (Mead et al. 2015).

We found evidence of transcriptional activity beyond the annotated genes at the MAT1 locus. Transcribed regions corresponded to the dMAT1-1-1 sequence $3^{\prime}$ of the MAT1-2 idiomorph in M. fructicola and to the dMAT1-2-1 sequence 5' of the MAT1-1 idiomorph in $M$. laxa. This finding agrees with the observed transcription of the MAT1-1-1 gene fragments derived from inversion or deletion events in homothallic Sclerotinia species (Chitrampalam and Pryor 2015; Chitrampalam et al. 2013; Xu et al. 2016). The regions also contained spliced transcripts with an antisense orientation, as could be deduced from the sequence of the splice junctions. This could mean that $D M A T 1-1-1$ and $d M A T 1-2-1$ are actively transcribed gene fragments with a potential role in sexual reproduction like in S. sclerotiorum (Chitrampalam et al. 2013; Doughan and Rollins 2016). Nevertheless, further investigations are required to establish their function and role in mating. Antisense transcription of the MAT1-1-1 and the MAT1-2-1 proteincoding genes were also observed in M. fructicola and M. laxa, but not in M. fructigena probably due to the low read depth at the MAT1 locus in this species. We previously assessed the antisense transcription of the MAT1-2-1 gene in B. cinerea with isoforms from alternative splicing (De Miccolis Angelini et al. 2016), and transcript isoforms of both the MAT1-2-1 and MAT1-1-1 genes have been observed in S. sclerotiorum (Chitrampalam et al. 2013). Antisense transcription is currently recognized as an important regulator of gene expression, widespread among all life kingdoms, but poorly understood for its role in regulation of basic biological processes such as sexual reproduction, growth and development (Donaldson and Saville 2012; Brophy and Voigt 2016).

In conclusion, this study has clarified for the first time the bipolar heterothallic mating systems governing the sexual reproduction in the major brown rot pathogens $M$. fructicola, M. laxa, and $M$. fructigena through the identification and full characterization of the MAT1 loci for gene content, transcriptional activities and phylogenetic analysis of the mating-type genes. Monitoring of mating types in fungal samples from Italy and other worldwide areas showed that both two mating types are present at similar frequency in the pathogen's populations and hence there are not genetic obstacles to the occurrence of sexual reproduction. A PCR-based method for assessing mating type was made available and will be helpful for further monitoring program on high numbers of isolates within field populations. As to M. fructicola, a quarantine pathogen recently introduced in Europe, the genetic structure of its populations present in South Italy suggests that they are primarily clonal but show a certain extent of recombination deriving from the potential occurrence of sexual reproduction. These results contribute to a deeper knowledge of the role of sexual reproduction in the evolution and population biology of these economically important brown rot pathogens.

\section{ACKNOWLEDGMENTS}

The cooperation of G. Romanazzi and L. Landi (Marche Polytechnic University, Ancona, Italy) to the in-progress sequencing project of Monilinia genomes is acknowledged.

\section{LITERATURE CITED}

Abate, D., Pastore, C., Gerin, D., De Miccolis Angelini, R. M., Rotolo, C., Pollastro, S., and Faretra, F. 2018. Characterization of Monilinia spp. populations on stone fruits in South Italy. Plant Dis. doi.org/10.1094/PDIS08-17-1314-RE.

Agapow, P. M., and Burt, A. 2001. Indices of multilocus linkage disequilibrium. Mol. Ecol. Notes 1:101-102.

Aldrich-Wolfe, L., Travers, S., and Nelson, B. D. 2015. Genetic variation of Sclerotinia sclerotiorum from multiple crops in the North Central United States. PLoS One 10:e139188.

Amselem, J., Cuomo, C. A., and van Kan, J. A. L. 2011. Genomic analysis of the necrotrophic fungal pathogens Sclerotinia sclerotiorum and Botrytis cinerea. PLoS Genet. 7:e1002230.

Batra, L. R. 1991. World species of Monilinia (fungi): Their ecology, biosystematics and control. Mycologia Mem. 16:1-246.

Becker, K., Beer, C., Freitag, M., and Kück, U. 2015. Genome-wide identification of target genes of a mating-type $\alpha$-domain transcription factor reveals functions beyond sexual development. Mol. Microbiol. 96:1002-1022.

Bidard, F., Ait Benkhali, J., and Coppin, E. 2011. Genome-wide gene expression profiling of fertilization competent mycelium in opposite mating types in the heterothallic fungus Podospora anserina. PLoS One 6:e21476.

Brophy, J. A., and Voigt, C. A. 2016. Antisense transcription as a tool to tune gene expression. Mol. Syst. Biol. 12:854.

Byrde, R. J. W., and Willetts, H. J. 1977. The Brown Rot Fungi of Fruit-Their Biology and Control. Pergamon Press, New York, NY.

Chitrampalam, P., Inderbitzin, P., Maruthachalam, K., Wu, B. M., and Subbarao, K. V. 2013. The Sclerotinia sclerotiorum mating type locus (MAT) contains a 3.6-kb region that is inverted in every meiotic generation. PLoS One 8:e56895.

Chitrampalam, P., and Pryor, B. M. 2015. Characterization of mating type (MAT) alleles differentiated by a natural inversion in Sclerotinia minor. Plant Pathol. 64:911-920.

De Cal, A., Egüen, B., and Melgarejo, P. 2014. Vegetative compatibility groups and sexual reproduction among Spanish Monilinia fructicola isolates obtained from peach and nectarine orchards, but not Monilinia laxa. Fungal Biol. 118:484-494.

De Miccolis Angelini, R. M., Habib, W., Rotolo, C., Pollastro, S., and Faretra, F. 2010. Selection, characterization and genetic analysis of laboratory mutants of Botryotinia fuckeliana (Botrytis cinerea) resistant to the fungicide boscalid. Eur. J. Plant Pathol. 128:185-199.

De Miccolis Angelini, R. M., Abate, D., Rotolo, C., Gerin, D., Pollastro, S., and Faretra, F. 2018. De novo assembly and comparative transcriptome analysis of Monilinia fructicola, Monilinia laxa and Monilinia fructigena, the causal agents of brown rot on stone fruits. BMC Genomics 19:436.

De Miccolis Angelini, R. M., Rotolo, C., Pollastro, S., and Faretra, F. 2016. Molecular analysis of the mating type (MAT1) locus in strains of the heterothallic ascomycete Botrytis cinerea. Plant Pathol. 65:1321-1332.

Debuchy, R., Berteaux-Leceleir, V., and Silar, P. 2010. Mating systems and sexual morphogenesis in ascomycetes. Pages 501-535 in: Cellular and Molecular Biology of Filamentous Fungi. K. A. Borkovich and D. J. Ebbole, eds. ASM Press, Washington, DC.

Debuchy, R., and Turgeon, B. G. 2006. Mating-type structure, evolution, and function in Euascomycetes. Pages 293-323 in: The Mycota I. Growth, Differentiation, and Sexuality. U. Kües and R. Fischer, eds. SpringerVerlag, Berlin, Germany.

Donaldson, M. E., and Saville, B. J. 2012. Natural antisense transcripts in fungi. Mol. Microbiol. 85:405-417.

Doughan, B., and Rollins, J. A. 2016. Characterization of MAT gene functions in the life cycle of Sclerotinia sclerotiorum reveals a lineage-specific $M A T$ gene functioning in apothecium morphogenesis. Fungal Biol. 120:1105-1117.

Dunn, A. R., Kikkert, J. R., and Pethybridge, S. J. 2017. Genotypic characteristics in populations of Sclerotinia sclerotiorum from New York State, USA. Ann. Appl. Biol. 170:219-228.

Ezekiel, W. N. 1924. Fruit-rotting Sclerotinias. II. The American brown-rot fungi. Md. Agric. Exp. Stn. Bull. 271:87-142.

Faretra, F., Antonacci, E., and Pollastro, S. 1988. Sexual behavior and mating system of Botryotinia fuckeliana, teleomorph of Botrytis cinerea. J. Gen. Microbiol. 134:2543-2550.

Ferreira, A. V. B., Saupe, S., and Glass, N. L. 1996. Transcriptional analysis of the mtA idiomorph of Neurospora crassa identifies two genes in addition to mtA-1. Mol. Gen. Genet. 250:767-774. 
Free, S. J., Holtz, B. A., and Michailides, T. J. 1996. Mating behavior in field populations of Monilinia fructicola in California. Mycologia 88:208-211.

Geng, Y., Li, Z., Xia, L. Y., Wang, Q., Hu, X. M., and Zhang, X. G. 2014. Characterization and phylogenetic analysis of the mating-type loci in the asexual ascomycete genus Ulocladium. Mycologia 106:649-665.

Harada, Y. 1977. Studies on the Japanese species of Monilinia (Sclerotiniaceae). Bull. Fac. Agric. Hirosaki Univ. 27:30-109.

Harada, Y., Nakao, S., Sasaki, M., Sasaki, Y., Ichihashi, Y., and Sano, T. 2004. Monilia mumecola, a new brown rot fungus on Prunus mume in Japan. J. Gen. Plant Pathol. 70:297-307.

Heitman, J. 2006. Sexual reproduction and the evolution of microbial pathogens. Curr. Biol. 16:R711-R725.

Holtz, B. A., Michailides, T. J., and Hong, C. X. 1998. Development of apothecia from stone fruit infected and stromatized by Monilinia fructicola in California. Plant Dis. 82:1375-1380.

Hu, M. J., Cox, K. D., Schnabel, G., and Luo, C. X. 2011. Monilinia species causing brown rot of peach in China. PLoS One 6:e24990.

Idnurm, A. 2011. Sex and speciation: The paradox that non-recombining DNA promotes recombination. Fungal Biol. Rev. 25:121-127.

Jana, T., Sharma, T. R., and Singh, N. K. 2005. SSR-based detection of genetic variability in the charcoal root rot pathogen Macrophomina phaseolina. Mycol. Res. 109:81-86.

Jänsch, M., Frey, J. E., Hilber, M., Broggini, G. A. L., Weger, J., Schnabel, G., and Patocchi, A. 2012. SSR marker analysis of Monilinia fructicola from Swiss apricots suggests introduction of the pathogen from neighboring countries and the United States. Plant Pathol. 61:247-254.

Kumar, S., Stecher, G., and Tamura, K. 2016. MEGA7: Molecular evolutionary genetics analysis version 7.0 for bigger datasets. Mol. Biol. Evol. 33:1870-1874.

Lee, D. H., Roux, J., Wingfield, B. D., and Wingfield, M. J. 2015. Variation in growth rates and aggressiveness of naturally occurring self-fertile and selfsterile isolates of the wilt pathogen Ceratocystis albifundus. Plant Pathol. 64:1103-1109.

Lim, S., Notley-McRobb, L., Lim, M., and Carter, D. A. 2004. A comparison of the nature and abundance of microsatellite in 14 fungal genomes. Fungal Genet. Biol. 41:1025-1036.

Longato, S., and Bonfante, P. 1997. Molecular identification of mycorrhizal fungi by direct amplification of microsatellite regions. Mycol. Res. 101:425-432.

Lopes, A., Phillips, A. J., and Alves, A. 2017. Mating type genes in the genus Neofusicoccum: Mating strategies and usefulness in species delimitation. Fungal Biol. 121:394-404.

Ma, Z., Luo, Y., and Michailides, T. J. 2003. Nested PCR assays for detection of Monilinia fructicola in stone fruit orchards and Botryosphaeria dothidea from pistachios in California. J. Phytopathol. 151:312-322.

Ma, Z., and Michailides, T. J. 2005. Genetic structure of Botrytis cinerea populations from different host plants in California. Plant Dis. 89:1083-1089.

Martin, T., Lu, S. W., and van Tilbeurgh, H. 2010. Tracing the origin of the fungal alpha1 domain places its ancestor in the HMG-box superfamily: Implication for fungal mating-type evolution. PLoS One 5:e15199.

Martini, C., Spadoni, A., and Mari, M. 2013. First report of brown rot caused by Monilinia fructicola on apple in Italy. Plant Dis. 97:689.

McDonald, B. A. 1997. The population genetics of fungi: Tools and techniques. Phytopathology 87:448-453.

Mead, M. E., Stanton, B. C., Kruzel, E. K., and Hull, C. M. 2015. Targets of the sex inducer homeodomain proteins are required for fungal development and virulence in Cryptococcus neoformans. Mol. Microbiol. 95:804-818.

Michailides, T. J., Lou, Y., Ma, Z., and Morgan, D. P. 2007. Brown rot of dried plum in California: New insight on an old disease. APSnet Feature Story. doi.org/10.1094/APSnetFeature-2007-0307

Mordue, J. E. M. 1979a. Sclerotinia fructicola. CMI Descriptions of Pathogenic Fungi and Bacteria No. 616. CAB International, Wallingford, UK.

Mordue, J. E. M. 1979b. Sclerotinia fructigena. CMI Descriptions of Pathogenic Fungi and Bacteria No. 617. CAB International, Wallingford, UK.

Mordue, J. E. M. 1979c. Sclerotinia laxa. CMI Descriptions of Pathogenic Fungi and Bacteria No. 619. CAB International, Wallingford, UK.

Ni, M., Feretzaki, M., Sun, S., Wang, X., and Heitman, J. 2011. Sex in fungi. Annu. Rev. Genet. 45:405-430.

O’Donnell, K., Ward, T. J., Geiser, D. M., Kistler, H. C., and Aoki, T. 2004. Genealogical concordance between the mating type locus and seven other nuclear genes supports formal recognition of nine phylogenetically distinct species within the Fusarium graminearum clade. Fungal Genet. Biol. 41: 600-623.

OEPP/EPPO. 2002. First report of Monilinia fructicola in France. EPPO Reporting Service 2002/003: No. 1. http://www.eppo.org

Ogawa, J. M., and English, H. 1991. Diseases of temperate zone tree fruit and nut crops. University of California Division of Agriculture and Natural Resources, Oakland, CA, Publication No. 3345.

Paoletti, M., Rydholm, C., Schwier, E. U., Anderson, M. J., and Szakacs, G. 2005. Evidence for sexuality in the opportunistic fungal pathogen Aspergillus fumigatus. Curr. Biol. 15:1242-1248.
Pellegrino, C., Gullino, M. L., Garibaldi, A., and Spadaro, D. 2009. First report of brown rot of stone fruit caused by Monilinia fructicola in Italy. Plant Dis. 93:668.

Pöggeler, S., Nowrousian, M., and Kück, U. 2006. Fruiting-body development in ascomycetes. Pages 325-355 in: Growth, Differentiation and Sexuality. U. Kües, R. Fischer, S. Pöggeler, M. Nowrousian, and U. Kück, eds. Springer, Berlin, Heidelberg.

Putman, A. I., Tredway, L. P., and Carbone, I. 2015. Characterization and distribution of mating-type genes of the turfgrass pathogen Sclerotinia homoeocarpa on a global scale. Fungal Genet. Biol. 81:25-40.

Riccioni, L., and Valente, M. T. 2015. Comparison of different PCR tests to identify Monilinia fructicola. Bull. OEPP 45:33-40.

Rodenburg, S. Y. A., Terhem, R. B., Veloso, J., Stassen, J. H. M., and van Kan, J. A. L. 2018. Functional analysis of mating type genes and transcriptome analysis during fruiting body development of Botrytis cinerea. MBio 9: e01939-e17.

Rozen, S., and Skaletsky, H. 2000. PRIMER3 on the WWW for general users and for biologist programmers. Pages 365-386 in: Bioinformatics Methods and Protocols: Methods in Molecular Biology. S. Krawetz and S. Misener, eds. Humana Press, Totowa, NJ.

Sharvell, E. G., and Chen, S. M. 1943. Cultural variation in single ascospore isolates of Sclerotinia fructicola (Wint.) Rehm. from cherry plume hybrids. Phytopathology 33:18.

Sonoda, R. M., Ogawa, J. M., Esser, T. E., and Manji, B. T. 1982. Mycelial interaction zones among single ascospore isolates of Monilinia fructicola. Mycologia 74:681-683.

Sterky, F., and Lundeberg, J. 2000. Sequence analysis of genes and genomes. J. Biotechnol. 76:1-31.

Strandberg, R., Nygren, K., Menkis, A., James, T. Y., Wik, L., Stajich, J. E., and Johannesson, H. 2010. Conflict between reproductive gene trees and species phylogeny among heterothallic and pseudohomothallic members of the filamentous ascomycete genus Neurospora. Fungal Genet. Biol. 47:869-878.

Terhem, R. B., Staats, M., and van Kan, J. A. L. 2015. Mating type and sexual fruiting body of Botrytis elliptica, the causal agent of fire blight in lily. Eur. J. Plant Pathol. 142:615-624.

Thind, K. S., and Keitt, G. W. 1949. Studies on variability of Sclerotinia fructicola (Wint.) Rehm. Phytopath. 39:621-636.

Trapnell, C., Williams, B. A., Pertea, G., Mortazavi, A., Kwan, G., and van Baren, M. J. 2010. Transcript assembly and quantification by RNA-Seq reveals unannotated transcripts and isoform switching during cell differentiation. Nat. Biotechnol. 28:511-515.

Tsui, C. K. M., DiGuistini, S., and Wang, Y. 2013. Unequal recombination and evolution of the mating-type (MAT) loci in the pathogenic fungus Grosmannia clavigera and relatives. G3 (Bethesda) 3:465-480.

Váczy, K. Z., Sándor, E., Karaffa, L., Fekete, E., Fekete, E., Arnyasi, M., Czeglédi, L., Kövics, G. J., Druzhinina, I. S., and Kubicek, C. P. 2008. Sexual recombination in the Botrytis cinerea populations in Hungarian vineyards. Phytopathology 98:1312-1319.

van Leeuwen, G. C., Baayen, R. P., Holb, I. J., and Jeger, M. J. 2002. Distinction of the Asiatic brown rot fungus Monilia polystroma sp. nov. from M. fructigena. Mycol. Res. 106:444-451.

Villarino, M., Larena, I., Melgarejo, P., De Cal, A., and Martinez, F. 2012. Analysis of genetic diversity in Monilinia fructicola from the Ebro Valley in Spain using ISSR and RAPD markers. Eur. J. Plant Pathol. 132:511524.

Wang, Q., Wang, S., Xiong, C. L., James, T. Y., and Zhang, X. G. 2017. Mating-type genes of the anamorphic fungus Ulocladium botrytis affect both asexual sporulation and sexual reproduction. Sci. Rep. 7:7932

Wessels, B. A., Linde, C. C., Fourie, P. H., and Mostert, L. 2016. Genetic population structure and fungicide resistance of Botrytis cinerea in pear orchards in the Western Cape of South Africa. Plant Pathol. 65: 1473-1483.

Wilken, P. M., Steenkamp, E. T., Wingfield, M. J., De Beer, Z. W., and Wingfield, B. D. 2017. Which MAT gene? Pezizomycotina (Ascomycota) mating-type gene nomenclature reconsidered. Fungal Biol. Rev. 31: 199-211.

Willetts, H. J., and Harada, Y. 1984. A review of apothecial production of Monilinia fungi in Japan. Mycologia 76:314-325.

$\mathrm{Xu}$, J. 2006. Fundamentals of fungal molecular population genetic analyses. Curr. Issues Mol. Biol. 8:75-89.

Xu, L., Jardini, T. M., and Chen, W. 2016. Direct repeat-mediated DNA deletion of the mating type MAT1-2 genes results in unidirectional mating type switching in Sclerotinia trifoliorum. Sci. Rep. 6:27083.

Yin, L.-F., Chen, S.-N., Chen, G.-K., Schnabel, G., Du, S.-F., Chen, C., Li, G.-Q., and Luo, C.-X. 2015. Identification and characterization of three Monilinia species from plum in China. Plant Dis. 99:1775-1783.

Zhou, S., Smith, D. R., and Stanosz, G. R. 2001. Differentiation of Botryosphaeria species and related anamorphic fungi using inter simple or short sequence repeat (ISSR) fingerprinting. Mycol. Res. 105:919-926. 
ERRATUM / Volume 108, Number 11, 2018 / PHYTO-03-18-0074-R

In the article "Mating System in the Brown Rot Pathogens Monilinia fructicola, M. laxa, and M. fructigena" by D. Abate, R. M. De Miccolis Angelini, C. Rotolo, S. Pollastro, and F. Faretra, there were errors in the sequences of primer pairs $1 \mathrm{~B}$ and $2 \mathrm{C}$ in Table 2 . The correct sequences are shown below in revised Table 2 .

\section{Revised Table 2}

TABLE 2. Primer pairs used to determine the mating type of Monilinia species

\begin{tabular}{|c|c|c|c|c|c|}
\hline Idiomorph & Primer pair & & Sequence $\left(5^{\prime}-3^{\prime}\right)$ & Annealing temperature $\left({ }^{\circ} \mathrm{C}\right)$ & Amplicon size (bp) \\
\hline \multirow[t]{4}{*}{ MAT1-1 } & \multirow[t]{2}{*}{$1 \mathrm{~A}$} & Fw & ATATGGTGCCTGGGAGATGC & \multirow[t]{2}{*}{54} & \multirow[t]{2}{*}{166} \\
\hline & & Rev & AGCCATCATACCAGTGGACC & & \\
\hline & \multirow[t]{2}{*}{ 1B } & Fw & CATTGCTTCCACTCAGAATGC & \multirow[t]{2}{*}{54} & \multirow[t]{2}{*}{182} \\
\hline & & $\operatorname{Rev}$ & TCATACCAGTGGACCAAGGAG & & \\
\hline \multirow[t]{12}{*}{ MAT1-2 } & \multirow[t]{2}{*}{$2 \mathrm{~A}$} & Fw & TCCCACGTCCMGCTAATGAG & \multirow[t]{2}{*}{54} & \multirow[t]{2}{*}{246} \\
\hline & & Rev & AGCCTTCTTGTGAGCTTCCT & & \\
\hline & \multirow[t]{2}{*}{$2 \mathrm{~B}$} & Fw & CTCAAGCCAAAGATCCCACG & \multirow[t]{2}{*}{54} & \multirow[t]{2}{*}{223} \\
\hline & & Rev & RATCTTGTACTTCARRCGCC & & \\
\hline & \multirow[t]{2}{*}{$2 \mathrm{C}$} & Fw & AGGAAAGCTTATCCAGGGTATCA & \multirow[t]{2}{*}{60} & \multirow[t]{2}{*}{150} \\
\hline & & $\operatorname{Rev}$ & TATTTCAAGCGTCGTTCCGG & & \\
\hline & \multirow[t]{2}{*}{$2 \mathrm{D}$} & Fw & TCAAGGAAAGCTTATCCAGGGT & \multirow[t]{2}{*}{60} & \multirow[t]{2}{*}{204} \\
\hline & & Rev & AGCCTTCTTGTGAGCTTCCT & & \\
\hline & \multirow[t]{2}{*}{$2 \mathrm{E}$} & $\mathrm{Fw}$ & AGCTTCAATTATCGCTGGCA & \multirow[t]{2}{*}{60} & \multirow[t]{2}{*}{158} \\
\hline & & Rev & AGCCTTCTTGTGAGCTTCCT & & \\
\hline & \multirow[t]{2}{*}{$2 \mathrm{~F}$} & Fw & CCCCGCTATGATTTCAATTTTCT & \multirow[t]{2}{*}{60} & \multirow[t]{2}{*}{122} \\
\hline & & Rev & TTCCTTCAAAACATCGGCGC & & \\
\hline
\end{tabular}

a Primer pairs used for assessing the mating type of field isolates are in bold.

\section{Previously Published Version}

TABLE 2. Primer pairs used to determine the mating type of Monilinia species ${ }^{\mathrm{a}}$

\begin{tabular}{|c|c|c|c|c|c|}
\hline Idiomorph & Primer pair & & Sequence $\left(5^{\prime}-3^{\prime}\right)$ & Annealing temperature $\left({ }^{\circ} \mathrm{C}\right)$ & Amplicon size (bp) \\
\hline \multirow[t]{4}{*}{ MAT1-1 } & $1 \mathrm{~A}$ & Fw & ATATGGTGCCTGGGAGATGC & 54 & 166 \\
\hline & & Rev & AGCCATCATACCAGTGGACC & & \\
\hline & 1B & Fw & CATTGCTTCCACTCAGATGC & 54 & 182 \\
\hline & & Rev & TCATACCAGTGGACCAAGGAG & & \\
\hline \multirow[t]{12}{*}{$M A T 1-2$} & $2 \mathrm{~A}$ & Fw & TCCCACGTCCMGCTAATGAG & 54 & 246 \\
\hline & & Rev & AGCCTTCTTGTGAGCTTCCT & & \\
\hline & $2 \mathrm{~B}$ & Fw & CTCAAGCCAAAGATCCCACG & 54 & 223 \\
\hline & & Rev & RATCTTGTACTTCARRCGCC & & \\
\hline & $2 \mathrm{C}$ & Fw & AAGAAAGCTTATCCAGGTATCA & 60 & 150 \\
\hline & & Rev & TATTTCAAGCGTCGTTCCGG & & \\
\hline & $2 \mathrm{D}$ & FW & TCAAGGAAAGCTTATCCAGGGT & 60 & 204 \\
\hline & & Rev & AGCCTTCTTGTGAGCTTCCT & & \\
\hline & $2 \mathrm{E}$ & Fw & AGCTTCAATTATCGCTGGCA & 60 & 158 \\
\hline & & Rev & AGCCTTCTTGTGAGCTTCCT & & \\
\hline & $2 \mathrm{~F}$ & Fw & CCCCGCTATGATTTCAATTTTCT & 60 & 122 \\
\hline & & Rev & TTCCTTCAAAACATCGGCGC & & \\
\hline
\end{tabular}

a Primer pairs used for assessing the mating type of field isolates are in bold. 